\title{
Estrogen/ERa signaling axis participates in osteoblast maturation via upregulating chromosomal and mitochondrial complex gene expressions
}

\author{
Pei-I Lin ${ }^{1}$, Yu-Ting Tai ${ }^{2}$, Wing P. Chan ${ }^{3}$, Yi-Ling Lin'2, Mei-Hsiu Liao ${ }^{1,2}$ and Ruei- \\ Ming Chen ${ }^{1,2,4}$ \\ ${ }^{1}$ Graduate Institute of Medical Sciences, College of Medicine, Taipei Medical University, Taipei, Taiwan \\ ${ }^{2}$ Cell Physiology and Molecular Image Research Center and Department of Anesthesiology, Wan Fang Hospital, Taipei Medical \\ University, Taipei, Taiwan \\ ${ }^{3}$ Department of Radiology, Wan Fang Hospital, Taipei Medical University, Taipei, Taiwan \\ ${ }^{4}$ Anesthesiology and Health Policy Research Center, Taipei Medical University Hospital, Taipei, Taiwan \\ Correspondence to: Ruei-Ming Chen, email: rmchen@tmu.edu.tw \\ Keywords: estrogen/ERa; osteoblast mineralization; ATP synthesis; genomic complex genes; mitochondrial COX I \\ Received: July 14, $2017 \quad$ Accepted: December 09, $2017 \quad$ Published: December 19, 2017 \\ Copyright: Lin et al. This is an open-access article distributed under the terms of the Creative Commons Attribution License 3.0 \\ (CC BY 3.0), which permits unrestricted use, distribution, and reproduction in any medium, provided the original author and source \\ are credited.
}

\section{ABSTRACT}

Estrogen deficiency usually leads to bone loss and osteoporosis in postmenopausal women. Osteoblasts play crucial roles in bone formation. However, osteoblast functions are influenced by mitochondrial bioenergetic conditions. In this study, we investigated the roles of the estrogen and estrogen receptor alpha (ERa) axis in mitochondrial energy metabolism and subsequent osteoblast mineralization. Exposure of rat calvarial osteoblasts to estradiol caused substantial improvements in alkaline phosphatase activities and cell calcification. In parallel, treatment of human osteoblast-like U20S cells, derived from a female osteosarcoma patient, with estradiol specifically augmented ERa levels. Sequentially, estradiol stimulated translocation of ERa to nuclei in human osteoblasts and induced expressions of genomic respiratory chain complex NDUFA10, UQCRC1, cytochrome c oxidase (COX)8A, COX6A2, COX8C, COX6C, COX6B2, COX412, and ATP12A genes. Concurrently, estradiol stimulated translocation of ERa to mitochondria from the cytoplasm. A bioinformatic search found the existence of four estrogen response elements in the 5'-promoter region of the mitochondrial cox $i$ gene. Interestingly, estradiol induced COX I mRNA and protein expressions in human osteoblasts or rat calvarial osteoblasts. Knocking-down ERa translation concurrently downregulated estradiol-induced COX I mRNA expression. Consequently, exposure to estradiol led to successive increases in the mitochondrial membrane potential, the mitochondrial enzyme activity, and cellular adenosine triphosphate levels. Taken together, this study showed the roles of the estradiol/ERa signaling axis in improving osteoblast maturation through upregulating the mitochondrial bioenergetic system due to induction of definite chromosomal and mitochondrial complex gene expressions. Our results provide novel insights elucidating the roles of the estrogen/ERa alliance in regulating bone formation. 


\section{INTRODUCTION}

Osteoporosis, one of the most impactful metabolic diseases in the elderly, is also called a silent disorder that is characterized by a decrease in the bone mineral density (BMD) and a $T$ score of $\leq-2.5$ [1]. According to statistical stratification of the International Osteoporosis Foundation, one-third of postmenopausal women may suffer from osteoporosis. In the clinic, vertebral fractures are a common complication and a lethal factor for osteoporotic patients [2]. Osteoporosis is attributed to multiple risk features, including genetics, lifestyle, the nutritional status, and personal and family histories. Among these factors, the aging-induced deficiency of estrogen, a major hormonal regulator of bone metabolism, plays a critical role in the pathophysiological incidence of osteoporosis [3]. Healthy bones are dynamically balanced by a process of bone remodeling involving osteoblast-mediated bone formation and osteoclast-mediated bone resorption [4]. An imbalance of bone remodeling may lead to bone diseases, such as osteoporosis and bone defects. Conventionally, a shortage of estrogen can stimulate osteoclastogenesis via activation of a receptor activator of the nuclear factor kappa-B ligand pathway $[5,6]$. Moreover, estrogen can improve bone formation by increasing osteoblast lifespans $[6,7]$. As a result, an estrogen deficiency in postmenopausal women induces bone resorption but represses bone formation. In osteogenesis and osteoclastogenesis, estrogen receptor alpha $(E R \alpha)$ functions as an effective receptor to transduce estrogen-induced messages in osteoblasts and osteoclasts [7]. Nakamura et al. reported that when depleting ER $\alpha$, trabecular bone mass is instantaneously lost [8]. A recent study showed that aging can reduce ER $\alpha$-directed mitochondrial suppression of glutamine anaplerosis and osteogenic differentiation in mesenchymal stem cells [9]. Accordingly, the estrogen/ER $\alpha$ signaling pathway is essential for maintaining bone health.

Adenosine triphosphate (ATP), an end product of aerobic respiration, functions as a coenzyme for intracellular energy transfer [10]. Mitochondria with double membranes provide an appropriate environment for ATP biosynthesis. A series of complexes, i.e., complexes I-IV, and ATP synthase are anchored in inner membranes of mitochondria to process respiratory electron chain reactions and consequent ATP production [10,11]. These mitochondrial complexes are organized by multifaceted proteins encoded by chromosomal and mitochondria genes [12]. In human mitochondria, there are 44, 4, 11, and 14 structural units that contribute to construction of complexes I, II, III, and IV, respectively [10, 12]. Among these human mitochondrial complex subunits, 7, 4, and 14 proteins are encoded by mitochondria to separately build up complexes I, III, and IV. In particular, cytochrome c oxidase (COX) I is one of three core components that construct redox-active centers in complex IV with other nuclear-encoded proteins [11]. A variety of intrinsic and extrinsic factors contribute to regulating expressions of these genomic and mitochondrial DNA-encoding complex genes [13]. Estrogen, one of these factors, is involved in mitochondrial energy metabolism. For example, estrogen is thought to be a master regulator of bioenergetic systems in the brain that control glucose transport and glycolysis [14]. Furthermore, estrogen can improve mitochondrial activities and neural health, so administration of this hormone may prevent Alzheimer's disease $[15,16]$. Hsieh et al. reported that sex hormones will be a novel therapeutic adjunct for traumatic injury since they can increase mitochondrial bioenergetics [17]. Notably, cellular ATP production and systemic estrogen levels decline with aging, to $<10 \mathrm{pg} / \mathrm{mL}$ in postmenopausal women [18]. Nevertheless, studies of connections among estrogen deficiency, bone remodeling, and mitochondrial bioenergetics are limited.

$\mathrm{ER} \alpha$, a ligand-activated transcription factor, is the major regulator transducing the effects of estrogen on bone metabolism [19]. Structurally, ER $\alpha$ is composed of several functional domains that are crucial for hormone binding, DNA association, and activation of transcription [20]. Following binding with estrogen to the hormone domain, $\mathrm{ER} \alpha$ is functionally activated and then translocated to nuclei or mitochondria $[14,21]$. Concurrently, the ligand-activated $\mathrm{ER} \alpha$ forms a dimer to induce multiple gene expressions by binding to estrogen response elements (EREs), a palindromic inverted repeat of 5'-GGTCAnnnTGACC-3', existing in the 5'-promoter regions of these specific genes. In healthy bones, ER $\alpha$ participates in maintaining a dynamic balance of bone remodeling through raising nuclearinitiated induction of the death ligand Fas gene that results in osteoclast apoptosis [22]. Otherwise, ER $\alpha$ dysfunction because of an estrogen deficiency reduces levels of the Fas protein and induces osteoclastogenesis and consequent an osteoporotic pathophysiology. Our previous study also showed that estrogen-activated ER $\alpha$ can induce expressions of cell differentiation-related bone morphogenetic protein-6, collagen type I, and osteocalcin genes in primary rat osteoblasts and accordingly stimulate cell maturation [23]. Recently, Huang et al. reported that ER $\alpha$ can increase mitochondrial glutaminase expression in mesenchymal stem cells [9]. However, the effects of the estrogen and ER $\alpha$ axis on regulating expressions of human mitochondrial energy metabolism-related complex genes are still little known. Thus, this study was aimed to investigate participation of the estrogen/ER $\alpha$ signaling axis in osteoblast maturation and possible mechanisms, especially in regulating expressions of genomic and mitochondrial complex genes.

\section{RESULTS}

\section{Estradiol improves ALP activity and osteoblast mineralization}

After exposure to the differentiation agent for 21 days, primary rat osteoblasts had grown compactly 
(Figure 1A, left panel). In contrast, rat calvarial osteoblasts were co-treated with estradiol and the differentiation agent produced calcified nodules (right panel). Furthermore, treatment of primary osteoblasts with estradiol led to a significant $55 \%$ increase in ALP activity compared to the control group (Figure 1B). Results of Alizarin red Sand von Kossa-staining protocols revealed that exposure of primary rat osteoblasts to estradiol induced greater cell mineralization (Figure 1C, 1E, right panels). These signals were quantified and statistically analyzed (Figure 1D, 1F). Administration of estradiol improved osteoblast calcification by 2.8- and 2.2-fold in the Alizarin red S- and von Kossa-staining protocols, respectively.

\section{Estradiol specifically augmented levels of cellular ER $\alpha$ in human osteoblasts}

Exposure of human osteoblast-like U2OS cells to estradiol for 1 and $6 \mathrm{~h}$ did not affect the cell morphology or cell number (Figure 2A, 2B). In contrast, after treatment with estradiol for 12 and $24 \mathrm{~h}$, numbers of human osteoblasts were augmented by $76 \%$ and $69 \%$, respectively (Figure 2A, 2B). ER $\alpha$ was detected in the untreated group (Figure 2C, top panel, lane 1). Administration of estradiol to human osteoblasts for $1 \mathrm{~h}$ did not change $\mathrm{ER} \alpha$ levels (lane 2). However, after exposure for 6, 12, and $24 \mathrm{~h}$, levels of ER $\alpha$ in human osteoblasts obviously increased (lanes 3-5). $\beta$-Actin was immunodetected as the internal standard (bottom panel). These protein bands were quantified and statistically analyzed (Figure 2D). Treatment of human osteoblasts with estradiol for 6,12 , and $24 \mathrm{~h}$ led to significant 2.4-, 2.8-, and 2.6-fold increases in cellular ER $\alpha$ levels, respectively. In comparison, ER $\beta$ was also immunodetected in untreated human osteoblasts (Figure 2E, top panel, lane 1). However, amounts of ER $\beta$ were not influenced by estradiol administration (lanes 2-5). Statistical analyses of these protein bands using $\beta$-actin as the internal control showed that estradiol did not affect levels of ER $\beta$ in human osteoblasts (Figure 2F).

\section{Estradiol stimulated translocation of ER $\alpha$ from the cytoplasm to nuclei}

In untreated human osteoblasts, low levels of ERa were detected (Figure 3A, top-left panel). Nevertheless, exposure of human osteoblasts to estradiol for 1, 6, 12, and $24 \mathrm{~h}$ increased amounts of cellular ER $\alpha$ in a timedependent manner (top panels). Nuclei were detected with propidium iodide dye (middle panels). The merged signals with cyan-blue color indicate colocalization of ER $\alpha$ in nuclei (bottom panels). After administration of estradiol, colocalized signals were time-dependently amplified. Merged signals were quantified and statistically analyzed (Figure 3B). Compared to the control group, treatment of human osteoblasts with estradiol for 12 and $24 \mathrm{~h}$ caused
$98 \%$ and $156 \%$ increases in translocation of ER $\alpha$ from the cytoplasm to nuclei.

\section{Activated ER $\alpha$ induces expressions of specific genomic complex genes}

In a quantitative PCR array, 87 human mitochondrial ATP synthesis-related genes could be analyzed, including 33 genes for complex I NADH coenzyme Q reductase (NDUFA1, NDUFA10, NDUFA11, NDUFA2, NDUFA3, NDUFA4, NDUFA5, NDUFA6, NDUFA7, NDUFA8, NDUFAB1, NDUFB10, NDUFB2, NDUFB3, NDUFB4, NDUFB5, NDUFB6, NDUFB7, NDUFB8, NDUFB9, NDUFC1, NDUFC2, NDUFS1, NDUFS2, NDUFS3, NDUFS4, NDUFS5, NDUFS6, NDUFS7, NDUFS8, NDUFV1, NDUFV2, and NDUFV3), four genes for complex II succinate coenzyme Q reductase (SDHA, $S D H B, S D H C$, and $S D H D$ ), eight genes for complex III coenzyme Q cytochrome c reductase $(B C S 1 L, C Y C 1$, UQCR11, UQCRC1, UQCRC2, UQCRFS1, UQCRH, and $U Q C R Q), 14$ genes for complex IV cytochrome c oxidase (COX4I1, COX4I2, COX5A, COX5B, COX6A1, СОХ6А2, СОХ6B1, СОХ6B2, СОХ6С, СОХ7А2, $C O X 7 A 2 L, C O X 7 B, C O X 8 A$, and $C O X 8 C$ ), and 25 genes for complex V ATP synthase (ATP12A, ATP4A, ATP4B, ATP5A1, ATP5B, ATP5C1, ATP5F1, ATP5G1, ATP5G2, ATP5G3, ATP5H, ATP5I, ATP5J, ATP5J2, ATP5L, ATP5O, ATP6V0A2, ATP6V0D2, ATP6V1C2, ATP6V1E2, ATP6V1G3, LHPP, OXA1L, PPA1, and PPA2) (Figure $4 A)$. Differential expressions of these human genomic complex genes in human osteoblasts after exposure to estradiol are shown in Figure 4B. Data analyses further showed that estradiol administration induced nine (11\%), inhibited $33(39 \%)$, and did not affect $42(50 \%)$ gene expressions in human osteoblasts (Figure 4C). In detail, the upregulated genes were COX8A (complex IV), NDUFA10 (complex I), COX6A2 (complex IV), COX8C (complex IV), COХ6C (complex IV), UQCRC1 (complex III), COX6B2 (complex IV), ATP12A (complex V), and COX412 (complex IV) (Figure 4D).

\section{Estradiol stimulated translocation of ER $\alpha$ to mitochondria}

Treatment of human osteoblasts with estradiol for $1,6,12$, and $24 \mathrm{~h}$ increased levels of ER $\alpha$ in a timedependent manner (Figure 5A, top panel). Mitochondria were detected by staining with DiOC6 (middle panels). Merged signals with yellow color indicate colocalization of ER $\alpha$ and mitochondria (bottom panel). These merged signals were quantified and statistically analyzed (Figure 5B). Exposure of human osteoblasts to estradiol for 1, 6 , 12 , and $24 \mathrm{~h}$ led to noteworthy $95 \%, 122 \%, 161 \%$, and $206 \%$ enhancements in translocation of ER $\alpha$ from the cytoplasm to mitochondria, respectively. 


\section{Participation of ER $\alpha$ in regulating mitochondrial COX I and COX II gene expressions}

Our results from a bioinformatics approach revealed that four and six EREs respectively existed in the 5'-promoter regions of the cox $i$ and cox $i i$ genes. In untreated human osteoblasts, low levels of mitochondrial COX I mRNA were detected (Figure 6A, top panel, lane 1). After exposure to estradiol for $1 \mathrm{~h}$, COX I mRNA was not influenced (lane 2). However, treatment of human osteoblasts with estradiol for 3 , $6,12,18$, and $24 \mathrm{~h}$ led to time-dependent induction of

A
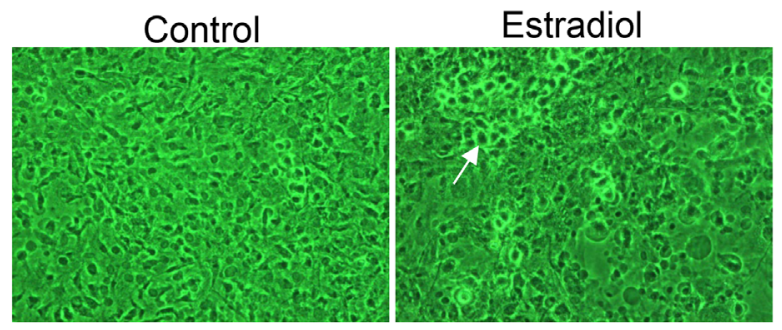

C

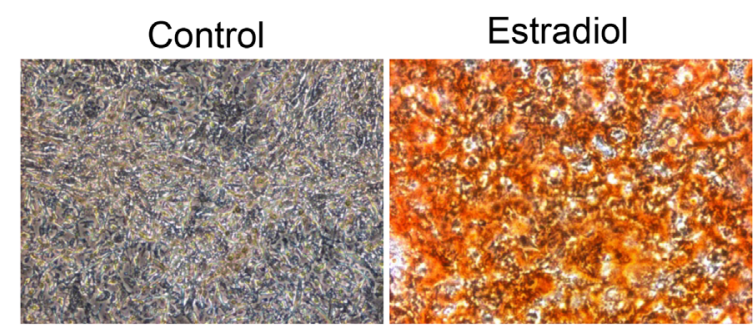

E
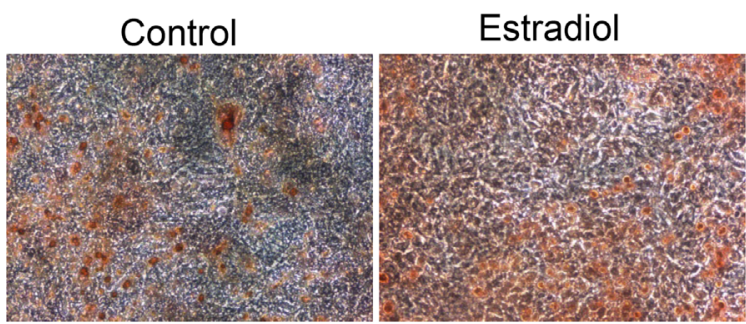

mitochondrial COX I mRNA (lanes 3-7). In parallel, exposure of human osteoblasts to estradiol induced mitochondrial COX II mRNA expression in a timedependent manner (Figure 6C, top panel). $\beta$-Actin mRNA was analyzed as the internal controls (Figure 6A, 6C, bottom panels). These bands were quantified and statistically analyzed (Figure 6B, 6D). Treatment of human osteoblasts with estradiol for $3,6,12,18$, and $24 \mathrm{~h}$ induced mitochondrial COX I mRNA by 1.8-, 3.0-, 2.9-, 2.8-, and 2.8-fold, respectively (Figure 6B). In contrast, amounts of mitochondrial COX II mRNA in human osteoblasts were respectively induced by $2.2-$,

B
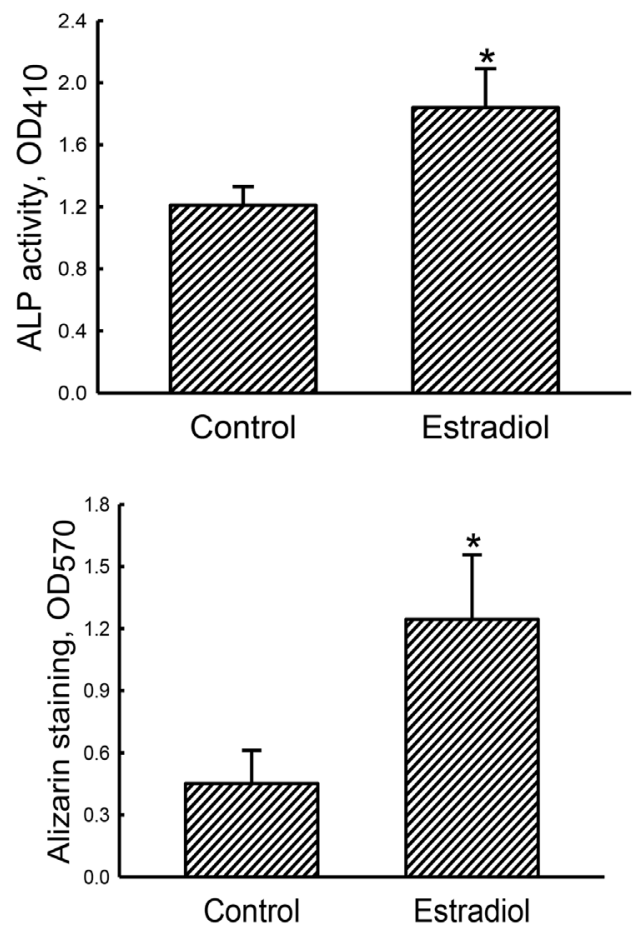

$\mathrm{F}$

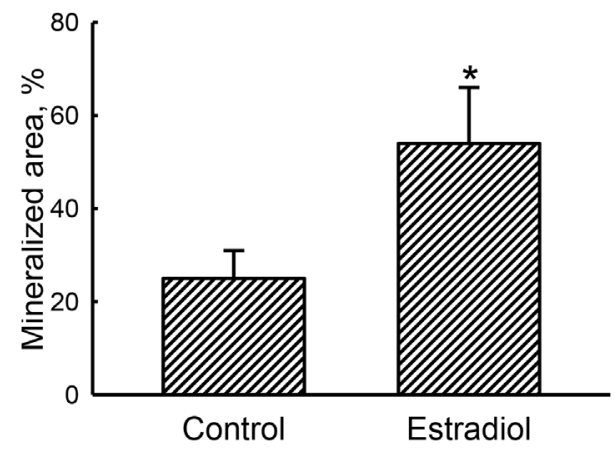

Figure 1: Effects of estradiol on osteoblast maturation. Primary rat osteoblasts isolated from neonatal calvarias were exposed to a combination of estradiol $(10 \mathrm{nM})$ and the differentiation agent, including dexamethasone, ascorbic acid, and $\beta$-glycerophosphate, for 21 days. Control cells received the differentiation agent only. Cell morphology was observed using a light microscope (A). The symbol, $\rightarrow$, indicates a calcified nodule. Alkaline phosphatase (ALP) activity was assayed with a colorimetric method (B). Mineralized nodules were stained using Alizarin red S- (C) and the von Kossa-staining (E) protocols. These nodule signals were quantified and statistically analyzed (D and F). Each value represent the mean \pm SEM for $n=6$. The symbol * indicates that the value significantly differed from the respective control group, $p<0.05 .100 \mathrm{x}$. 

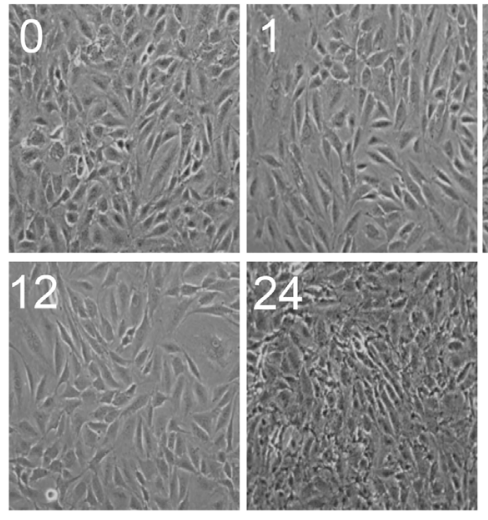

C

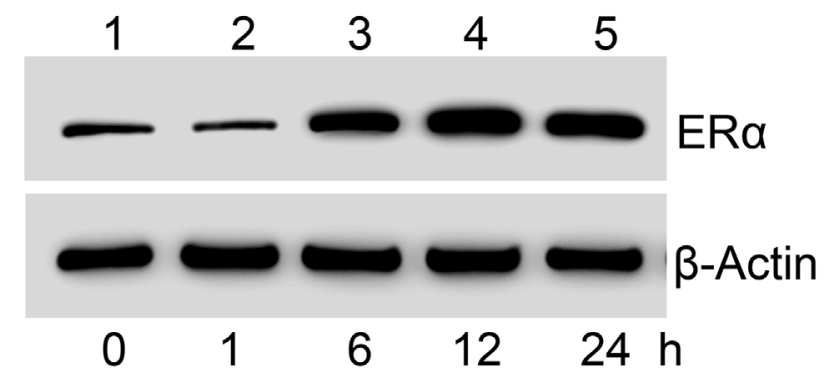

$\mathrm{E}$

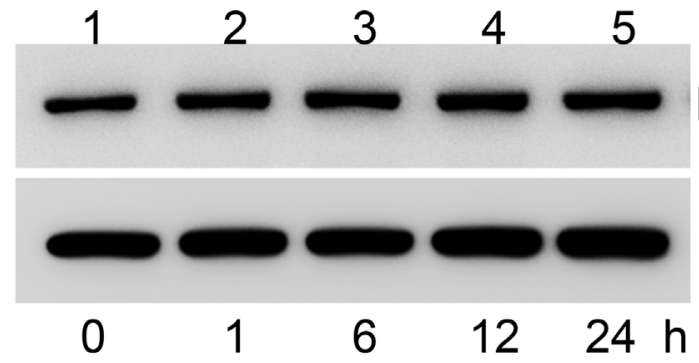

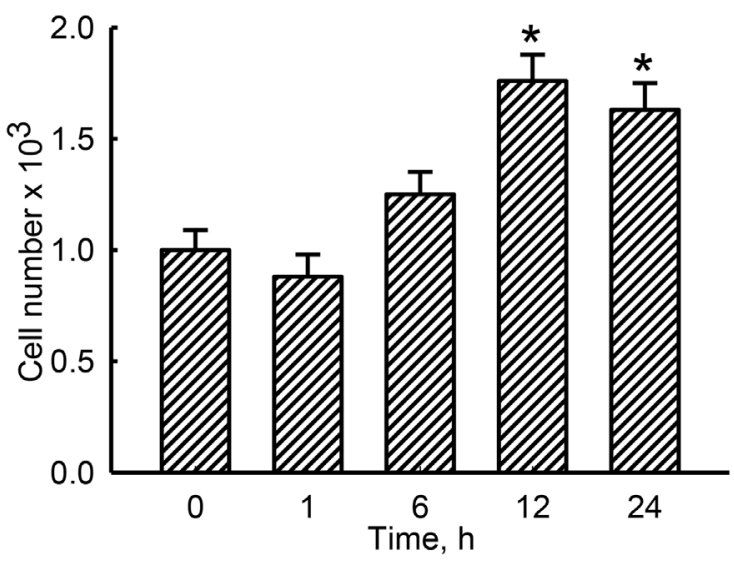

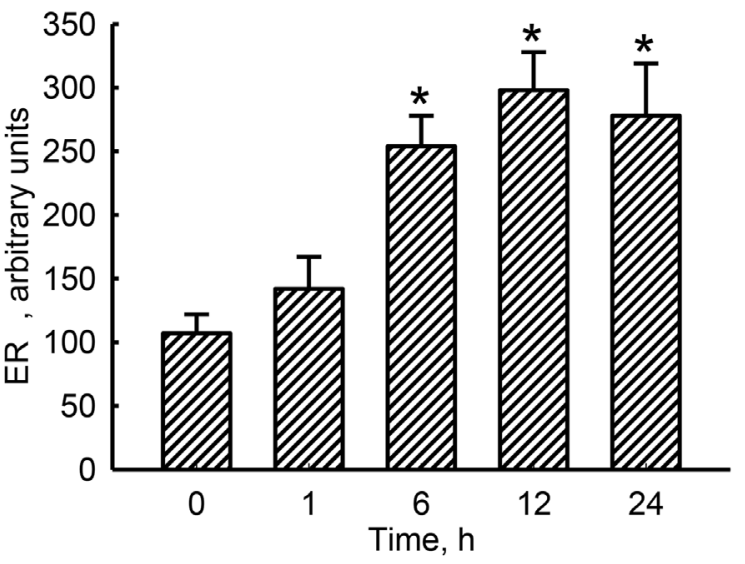

$\mathrm{F}$

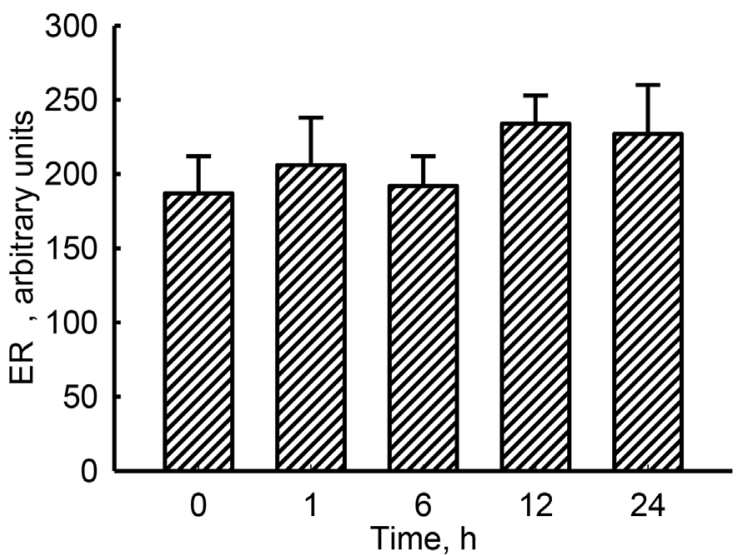

Figure 2: Effects of estradiol on levels of estrogen receptor alpha (ER $\alpha)$ and ERß proteins. Human osteoblast-like U2OS cells were exposed to $10 \mathrm{nM}$ of estradiol for 1, 6, 12, and $24 \mathrm{~h}$. Cell morphology was observed with a light microscope (A). Cell proliferation was analyzed using a trypan blue exclusion assay (B). After drug administration, cellular proteins were prepared for immunoblot analyses. Levels of ER $\alpha$ and ER $\beta$ were immunodetected (C and $\mathbf{E}$, top panels). Amounts of $\beta$-actin were analyzed as the internal standard $(\mathbf{C}$ and $\mathbf{E}$, bottom panels). These protein bands were quantified and statistically analyzed (D and $\mathbf{F})$. Each value represents the mean $\pm \operatorname{SEM}$ for $n=$ 6 . The symbol * indicates that the values significantly $(p<0.05)$ differed from the respective control group, $p<0.05$. 
2.5-, 3.7-, 2.5-, and 2-fold after exposure to estradiol for $3,6,12,18$, and $24 \mathrm{~h}$ (Figure 6D). A quantitative real-time PCR analysis was carried out to confirm that estradiol caused 2.5- and 3.7-fold increases in levels of COX I mRNA in human osteoblasts and rat calvarial cells, respectively (Figure 6E).
Estradiol specifically augmented mitochondrial COX I levels and consequently stimulated mitochondrial bioenergetic activation

Basal levels of mitochondrial COX I were detected (Figure 7A, top panel, lane 1). Exposure of human

A

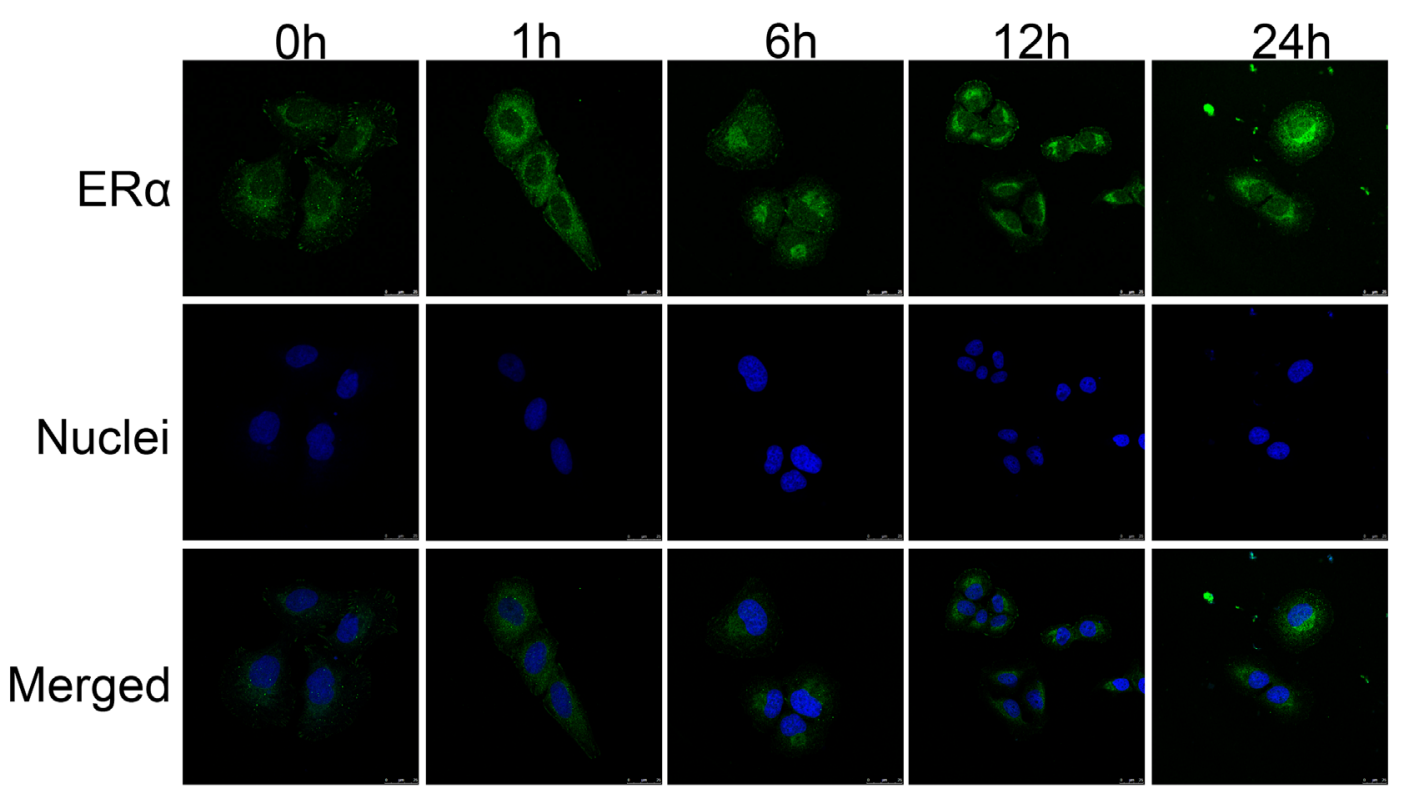

B

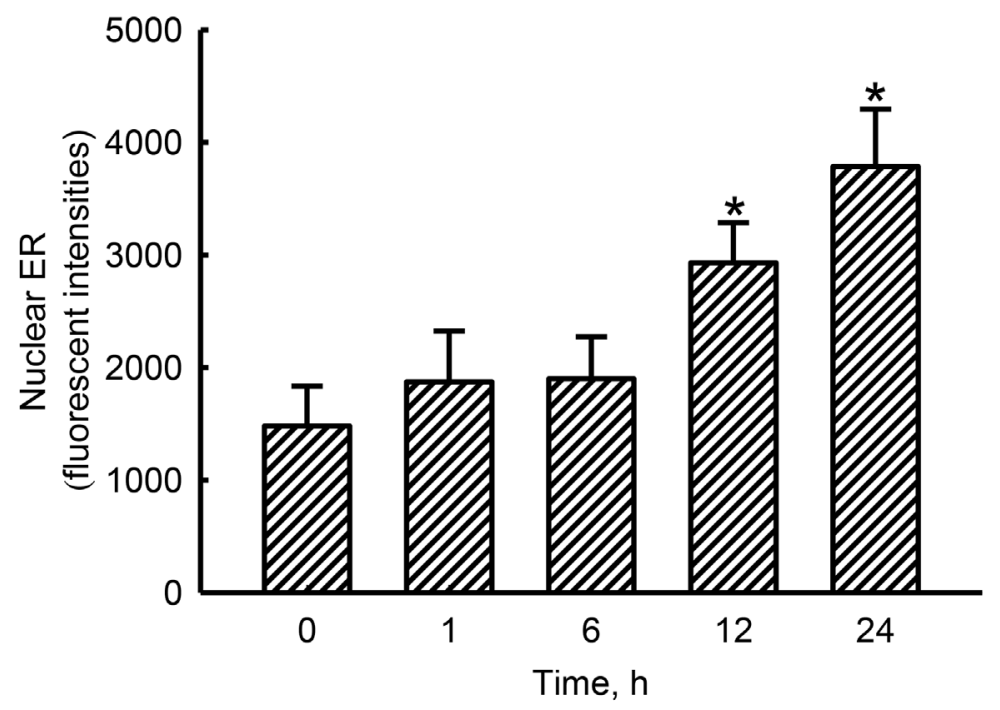

Figure 3: Effects of estradiol on translocation of estrogen receptor alpha (ERa) to nuclei. Human osteoblast-like U2OS cells were exposed to $10 \mathrm{nM}$ of estradiol for 1, 6, 12, and $24 \mathrm{~h}$. Distribution of the ER $\alpha$ protein in human osteoblasts was immunodetected using an antibody with Cy3-conjugated streptavidin (A, top panel). Cellular nuclei were stained with 4',6-diamidino-2-phenylindole (DAPI) (middle panel). The merged signals indicated that the ER $\alpha$ protein had been translocated into nuclei (bottom panel). These merged fluorescent signals were quantified and statistically analyzed (B). Each value represents the mean \pm SEM for $n=6$. The symbol ${ }^{*}$ indicates that the value significantly differed from the respective control group, $p<0.05$. 
osteoblasts to estradiol for $1 \mathrm{~h}$ did not change COX I levels (lane 2). In comparison, levels of mitochondrial COX I were obviously increased following estradiol treatment for 6,12 , and $24 \mathrm{~h}$ (lanes 3-5). $\beta$-Actin was immunodetected as the internal standard (bottom panel). These protein bands were quantified and statistically analyzed (Figure 7B). Six, 12, and 24 h later, treatment of human osteoblasts with estradiol led to 2.4-, 2.2-, and 2.1-fold growths in levels of COX I. In contrast, estradiol did not influence mitochondrial COX II levels (Figure 7C, 7D).

Exposure of human osteoblasts to estradiol for 1, 6,12 , and $24 \mathrm{~h}$ increased the mitochondrial membrane potential by $32 \%, 108 \%, 185 \%$, and $261 \%$, respectively (Figure 7E). In control human osteoblasts, the basal level of mitochondrial enzyme activity was detected (Figure 7F). Nonetheless, treatment with estradiol led to a significant $38 \%$ increase in the mitochondrial enzyme activity. Accordingly, compared to the untreated group, exposure to estradiol meaningfully elevated levels of cellular ATP in human osteoblasts by 52\% (Figure 7G).

\section{The estradiol-induced COX I mRNA expression was confirmed with a loss-of-function approach}

Compared to the control cells treated with scrambled siRNA, levels of ER $\alpha$ in human osteoblasts were decreased after applying ER $\alpha$ siRNA for 24 and $48 \mathrm{~h}$ (Figure 8A, top panel, lanes 1-3). $\beta$-Actin was analyzed as the internal control (bottom panel).
A

\begin{tabular}{|c|c|c|c|c|c|c|c|c|c|c|c|}
\hline ATPILA & AIPAA & $A A^{\prime} P A B$ & TPSAI & ATPSB & $\mathrm{PSCl}$ & (TPSFI & ATP5GI & ATPSG2 & ATPSG3 & ATPSH & ATPS| \\
\hline AOI & $A 02$ & 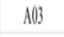 & A104 & A05 & A06 & A07 & & $A 09$ & tov & All & Al2 \\
\hline ATPJ] & ATPSI2 & & P50 & PGVOA2 & ATPGVOD2 & ATPGVICZ & & ATPGVIG3 & BCSIL & COX411 & COXAL2 \\
\hline BOI & BO2 & & $B O 4$ & & B06 & BO? & & $B O 9$ & & & B12 \\
\hline COXSA & COXSB & COX6Al & CXXA2 & COX6B। & COX6B? & $\mathrm{COX6C}$ & X7A2 & COX7A2L & & COX8A & $0 \times 8 C$ \\
\hline $\mathrm{COI}$ & $\mathrm{CO}$ & & $\infty$ & & & 007 & & COO & & col & $\mathrm{Cl} 2$ \\
\hline $\mathrm{CYCl}$ & IPP & NDUFAl & NDUFAlO & NDUFAll & IFA2 & NDUFA3 & FA4 & NDUFAS & FAG & DDUFA? & NDUFA8 \\
\hline DOI & D02 & & DO4 & & 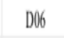 & D07 & & DOO & & DII & $\mathrm{DI} 2$ \\
\hline DUFAB| & NDUFBIO & & & & & DUFBG & & NDUFBS & & $\mathrm{FCl}$ & NDUFC? \\
\hline EDI & E0? & & & & & 507 & & 009 & & & El? \\
\hline NDUFS| & NDUFY? & NDUFS3 & NDUFS & NDUFSS & NDUFS & NDUFS9 & NDUFSS & NDUFVI & UFV? & NDUFV3 & 0XAlL \\
\hline $\mathrm{FOl}$ & $\mathrm{FO}$ & 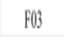 & $\mathrm{mu}$ & D.65 & ror & F0? & F08 & $\mathrm{FOO}$ & & Fil & $\mathrm{Fl} 2$ \\
\hline PPAI & 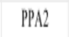 & & & & & VQCRII & LQCRCI & VOCRC2 & & UQCRH & UQCRQ \\
\hline c01 & 002 & 000 & 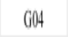 & cios & & 0.07 & $\cos$ & 609 & Gilo & Gill & Gil2 \\
\hline ACTB & PXY & GAPDH & HPRTI & RPLP & $H C D C$ & RTC & RTC & RTC & $\mathrm{PPC}$ & $P P C$ & $P P C$ \\
\hline HOI & HO2 & HO3 & HOH & HOS & HOO & HOP & H08 & HOO & HIO & HII & HI2 \\
\hline
\end{tabular}

C

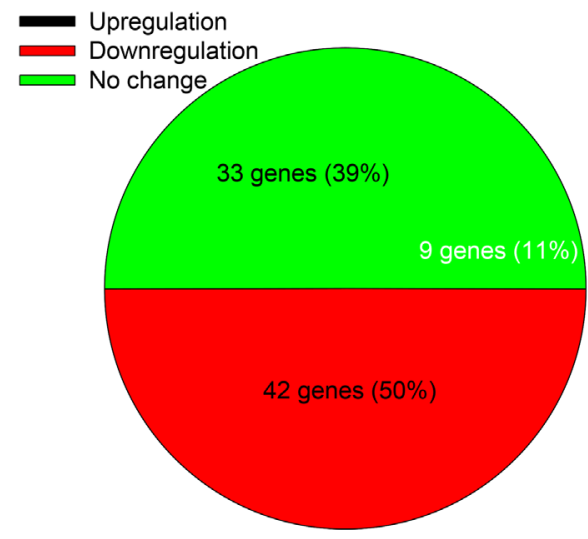

B

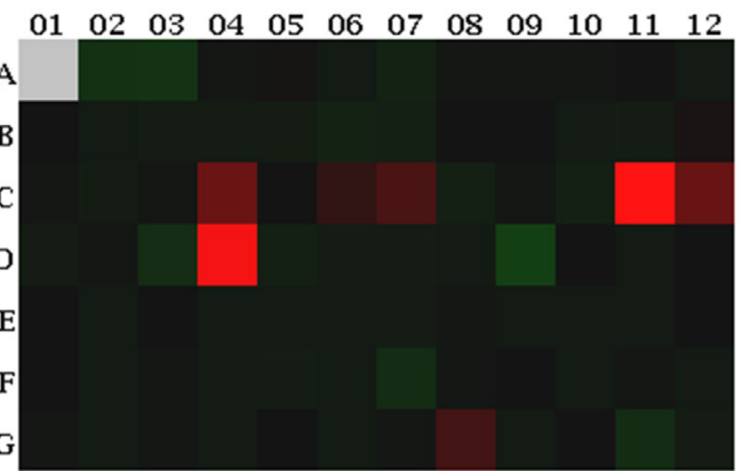

Magnitude of $\log 2$ (Fold Change)

D

Expressions of genomic mitochondrial complex genes induced after exposure to estradiol

\begin{tabular}{|c|c|c|}
\hline Genes & Complex & Folds \\
\hline COX8A & IV & 仓仓代 \\
\hline NDUFA10 & I & 仓仑 亿 \\
\hline COX6A2 & IV & 仓讠 \\
\hline COX8C & IV & 仓 \\
\hline cox6C & IV & 仓 \\
\hline UQCRC1 & III & 仓 \\
\hline Cox6B2 & IV & 仓 \\
\hline ATP12A & V & 仓 \\
\hline COX412 & IV & 仓 \\
\hline
\end{tabular}

Figure 4: Effects of estradiol on expressions of genomic ATP synthesis-related genes. Human osteoblast-like U2OS cells were treated with $10 \mathrm{nM}$ of estradiol for $48 \mathrm{~h}$. Total RNA were isolated for analysis of mitochondrial energy metabolism genes using a PCR array, containing 84 genomic genes encoding certain mitochondrial enzymes for ATP synthesis and 12 loading controls (A). Differential expressions of these genes were measured and shown as a hot map in the order of genes indicated in panel A(B). Percentages of upregulated, downregulated, and unchanged expressions of these genes were further statistically analyzed (C). Also, the major genomic complex genes upregulated by estradiol in human osteoblasts were summarized (D). 
These protein bands were quantified and statistically analyzed (Figure 8B). Treating with ER $\alpha$ siRNA for 24 and $48 \mathrm{~h}$ descend levels of ER $\alpha$ by $89 \%$ and $91 \%$, respectively. Exposure of human osteoblasts to estradiol induced mitochondrial COX I mRNA expression by 2.87 folds (Figure 8C). Application of ER $\alpha$ siRNA did not alter basal levels of mitochondrial COX I mRNA in human osteoblasts, but led to a significant $82 \%$ inhibition in estradiol-induced COX I mRNA expression (Figure 8C).
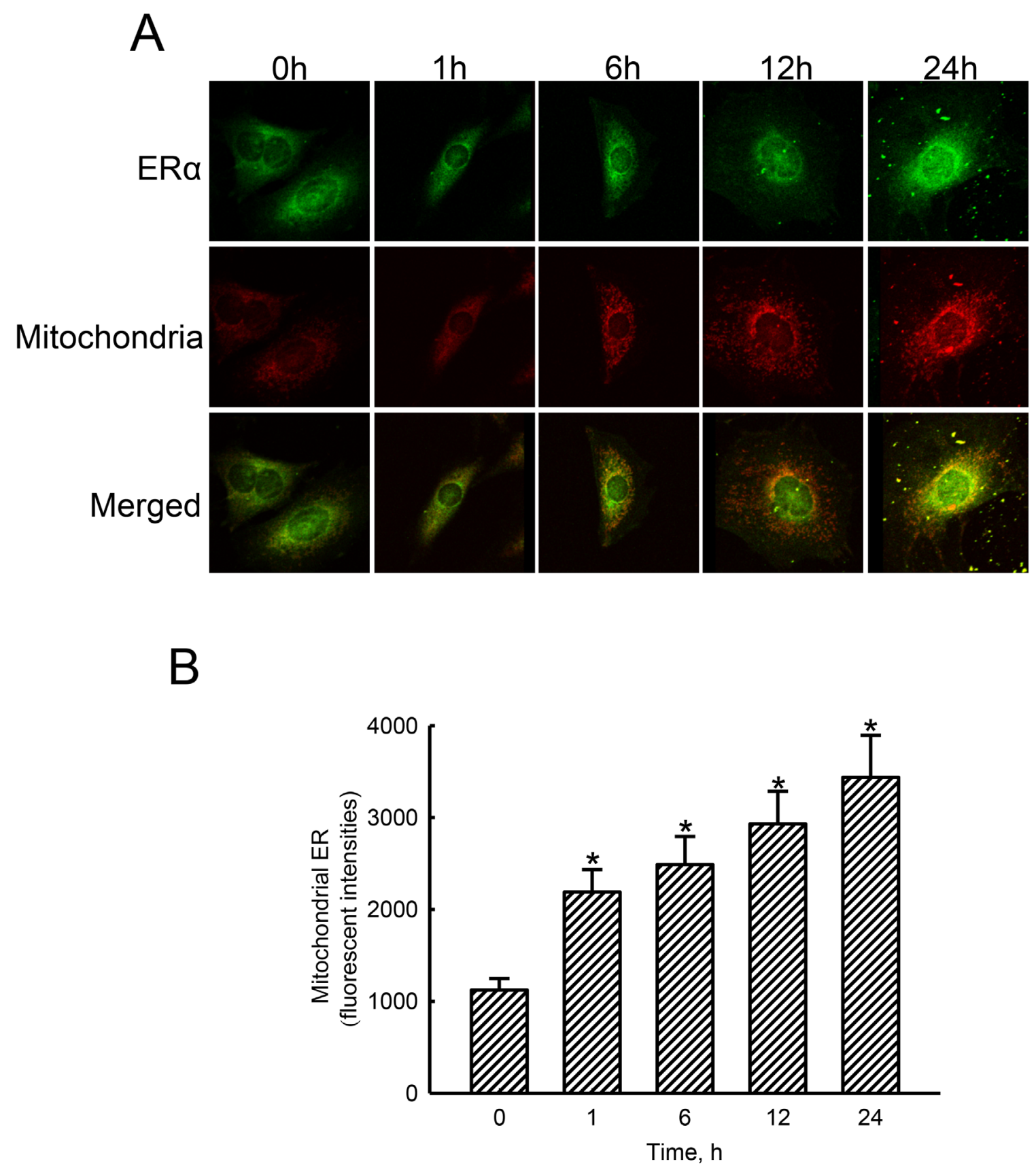

Figure 5: Effects of estradiol on translocation of estrogen receptor alpha (ER $\alpha)$ to mitochondria. Human osteoblastlike U2OS cells were exposed to $10 \mathrm{nM}$ of estradiol for 1, 6, 12, and $24 \mathrm{~h}$. Distribution of the ER $\alpha$ protein in human osteoblasts was immunodetected using an antibody with Cy3-conjugated streptavidin (A, top panel). Mitochondria of human osteoblasts were stained with 3,3'-dihexyloxacarbocyanine (DiOC6), a positively charged dye (middle panel). Merged signals indicated that the ER $\alpha$ protein had been translocated into mitochondria (bottom panels). These fluorescent signals were quantified and statistically analyzed (B). Each value represents the mean \pm SEM for $n=6$. The symbol ${ }^{*}$ indicates that the value significantly differed from the respective control group, $p<0.05$. 


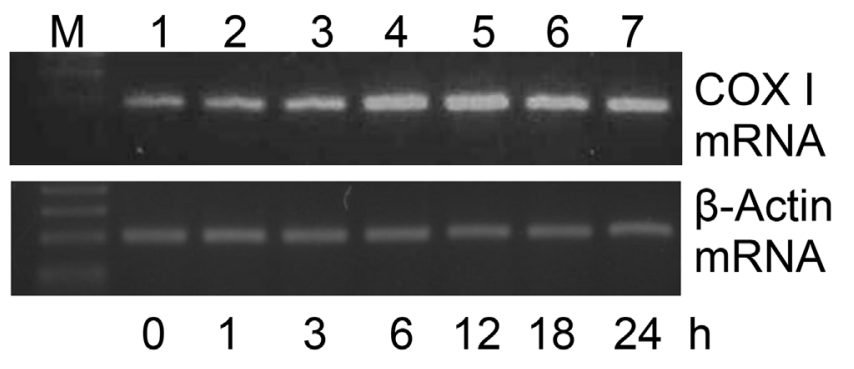

C

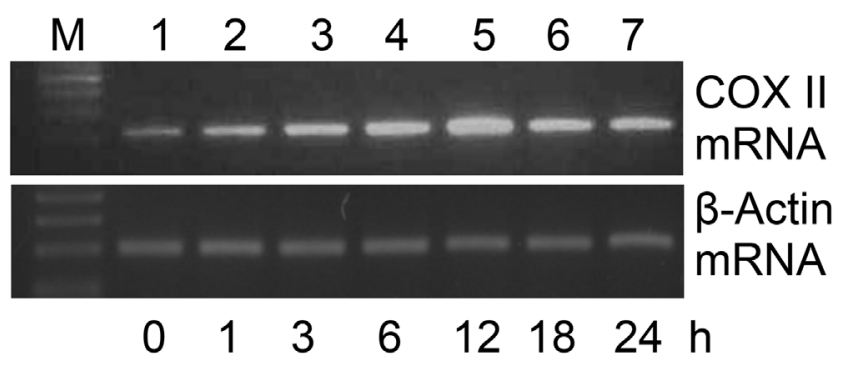

$\mathrm{E}$

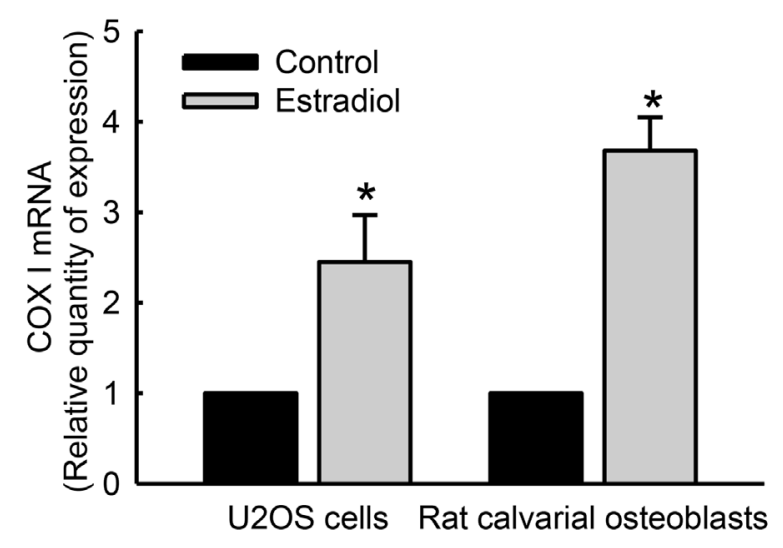

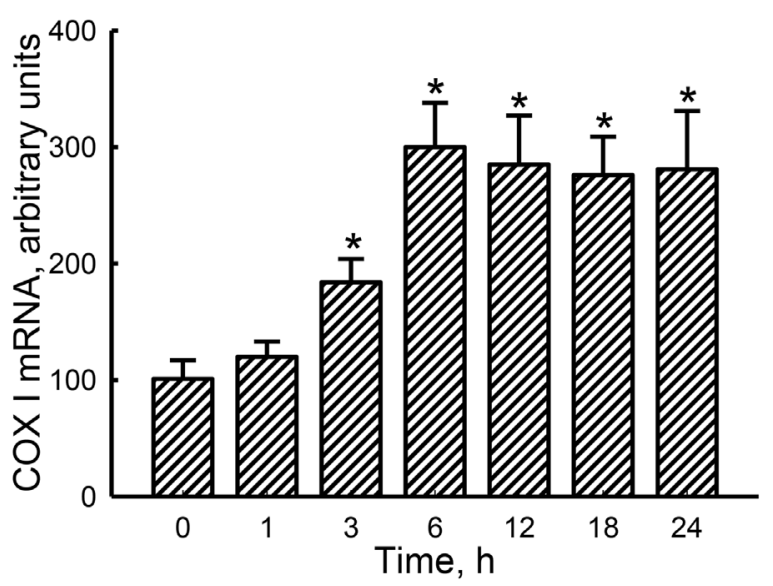

$\mathrm{D}$

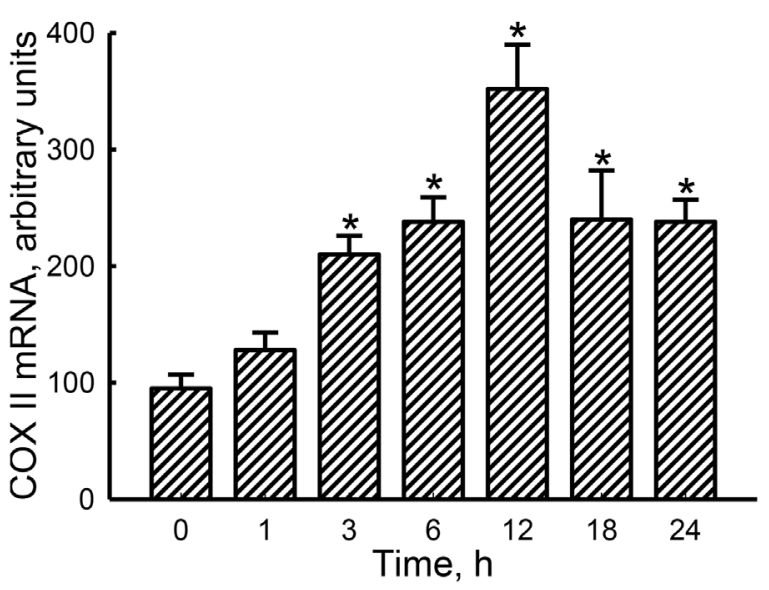

Figure 6: Effects of estradiol on induction of mitochondrial cytochrome c oxidase (COX) I and II mRNA expressions. Human osteoblast-like U2OS cells were exposed to $10 \mathrm{nM}$ of estradiol for 1, 3, 6, 12, 18, and $24 \mathrm{~h}$. Levels of COX I and II mRNA were analyzed using an RT-PCR (A and $\mathbf{C}$, top panels). Amounts of $\beta$-actin mRNA were assayed as the internal standard (bottom panel). These bands were quantified and statistically analyzed (B and D). A quantitative real-time PCR analysis was carried out to confirm expression of COX I mRNA in U2OS cells and rat calvarial osteoblasts (E). Each value represents the mean \pm SEM for $n=6$. The symbol ${ }^{*}$ indicates that the value significantly differed from the respective control group, $p<0.05$. 


\section{DISCUSSION}

This study demonstrated the participation of the estrogen/ER $\alpha$ signaling axis in regulation of osteoblast maturation possibly through stimulating mitochondrial bioenergetic metabolism. Our previous study also reported a similar result that genistein, a phytoestrogen, selectively induced ER $\alpha$ expression in mouse and rat osteoblasts [23]. In parallel with enhancing ER $\alpha$ expression, estradiol led to significant improvements in osteoblast activity, proliferation, and maturation. A continuous process of bone formation, called osteogenesis, comprises
A

C

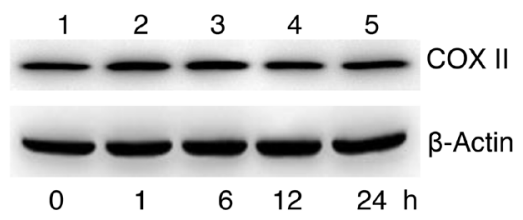

E

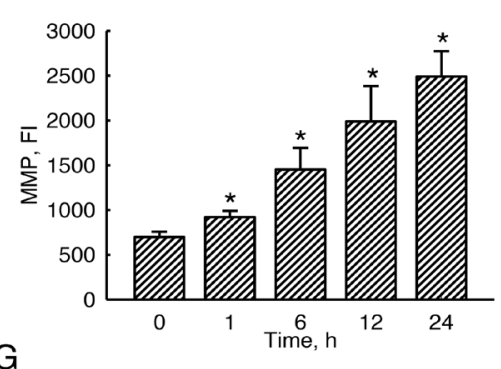

G
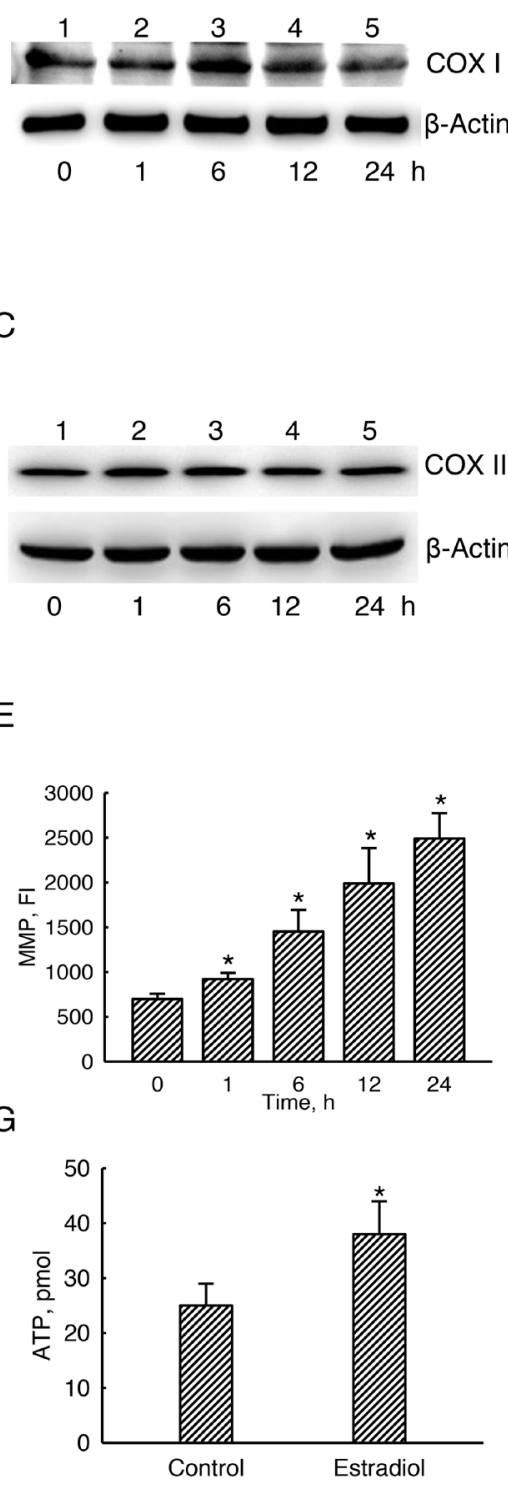

B
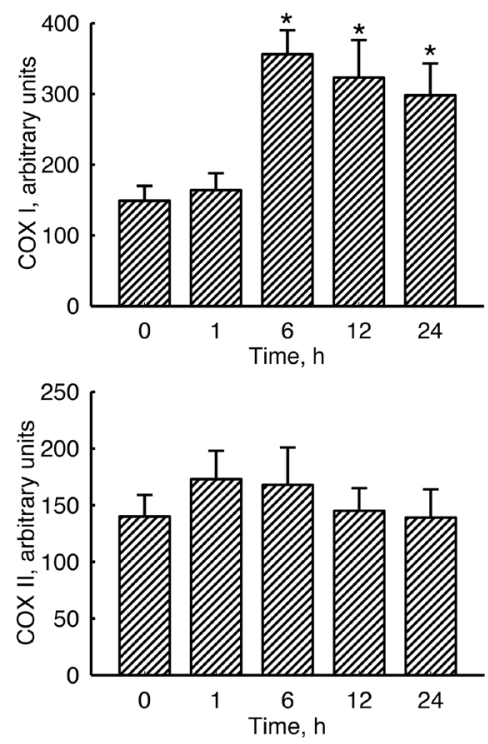

$\mathrm{F}$

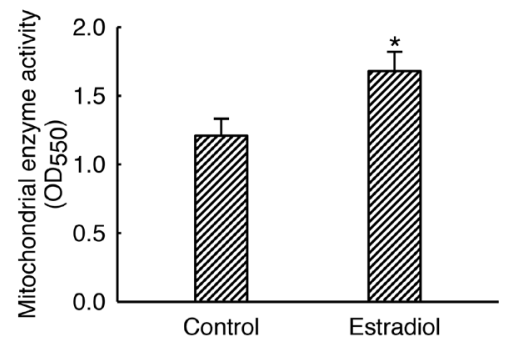

Figure 7: Effects of estradiol on mitochondrial cytochrome c oxidase (COX) I and II protein levels, mitochondrial enzyme activity, and cellular ATP amounts. Human osteoblast-like U2OS cells were exposed to $10 \mathrm{nM}$ of estradiol for 1, 6, 12, and $24 \mathrm{~h}$. Levels of COX I and II proteins were immunodetected (A and $\mathbf{C}$, top panels). Amounts of $\beta$-actin were analyzed as the internal standard (A and $\mathbf{C}$, bottom panels). These protein bands were quantified and statistically analyzed (B and $\mathbf{D})$. Mitochondria of human osteoblasts were stained with 3,3'-dihexyloxacarbocyanine (DiOC6), a positively charged dye. The mitochondrial membrane potential (MMP) of human osteoblasts was determined by quantifying DiOC6-positive signals (E). The mitochondrial enzyme activity was assayed using a colorimetric method (F). Cellular ATP levels were quantified using a bioluminescence assay (G). Each value represents the mean \pm SEM for $n=6$. The symbol ${ }^{*}$ indicates that the value significantly differed from the respective control group, $p<0.05$. FI, fluorescent intensity. 
three consecutive stages of osteoblast proliferation, differentiation, and mineralization [24, 25]. Hence, estrogen can improve osteoblast mineralization because of its effects of stimulating cell proliferation and cell activity,

A
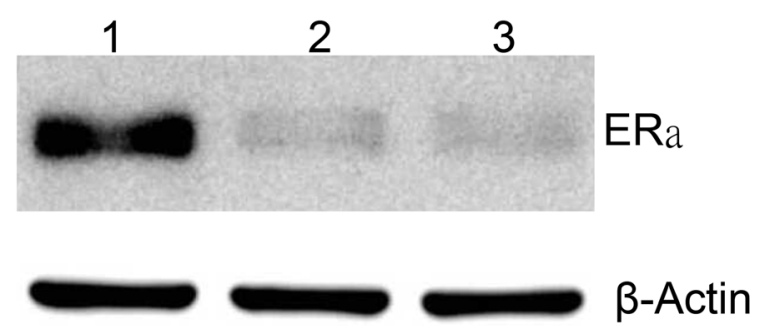

$0 \quad 24 \quad 48 \mathrm{~h}$

B
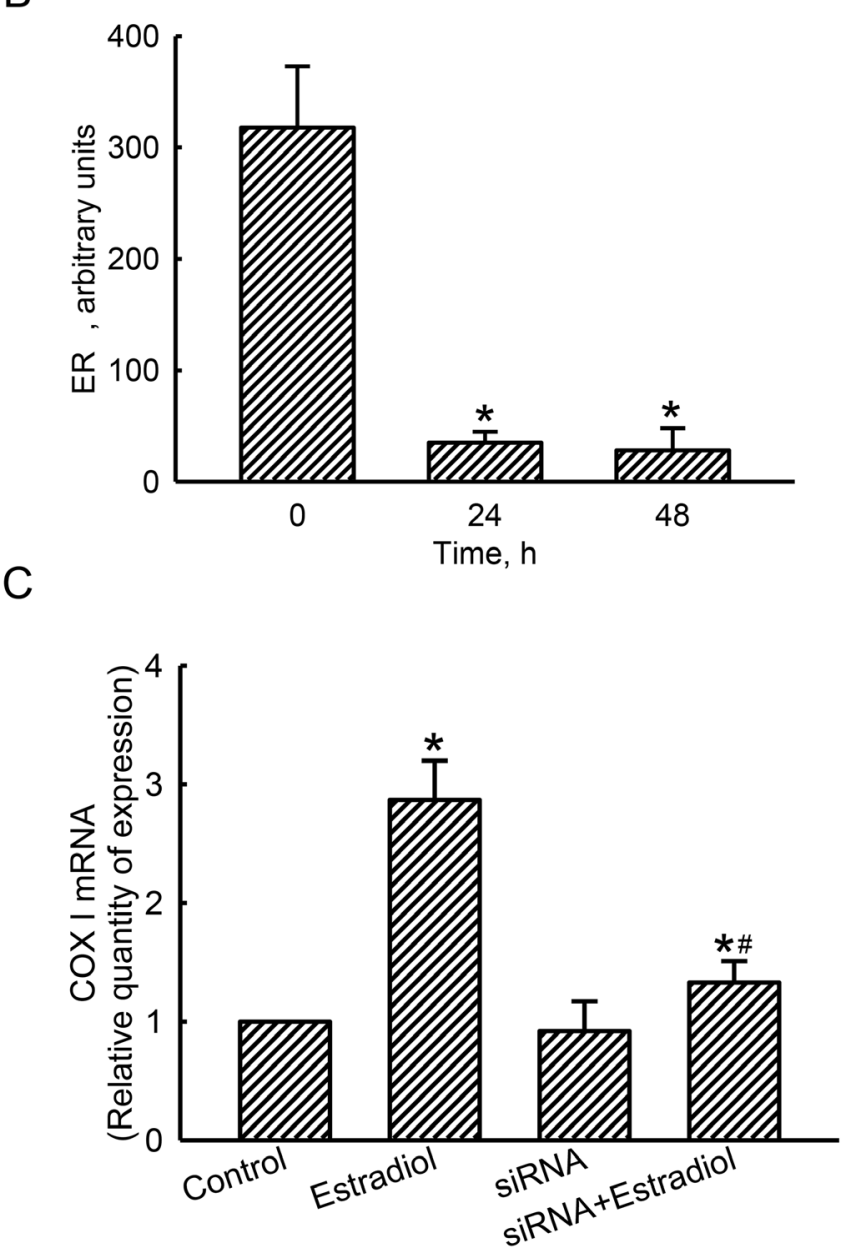

Figure 8: Effects of estrogen receptor alpha (ERa) knockdown on estradiol-induced mitochondrial cytochrome c oxidase (COX) I mRNA expression. Human osteoblast-like U2OS cells were treated with ER $\alpha$ siRNA for 24 and 48 h. Scrambled siRNA was administered to control cells as the negative standard. Levels of ER $\alpha$ were immunodetected (A, top panel). Amounts of $\beta$-actin were analyzed as the internal standard (bottom panel). These protein bands were quantified and statistically analyzed (B). After knocking-down ER $\alpha$ translation for $24 \mathrm{~h}$, human osteoblasts were treated with estradiol for another $6 \mathrm{~h}$. A quantitative PCR analysis was conducted to determine COX I mRNA expression (C). Each value represents the mean $\pm \mathrm{SEM}, n=3$. The symbols ${ }^{*}$ and ${ }^{\#}$ indicate that a value significantly $(p<0.05)$ differed from the control and estradioltreated groups, respectively. 
and this event may take place via an ER $\alpha$-dependent mechanism. In bone remodeling, maintenance of cellular ATP synthesis is essential for a dynamic balance between osteogenesis and osteoclastogenesis [26]. This study proved that estradiol enlarged the MMP, the mitochondrial enzyme activity, and ATP production in human osteoblasts. Therefore, estrogen can stimulate the mitochondrial bioenergetic system in osteoblasts and thus improve cell maturation. Our preliminary study showed the expression of ER $\alpha$ in human U2OS cells and rat calvarial osteoblasts. Compared to primary osteoblasts, human U2OS cells, derived from a female osteosarcoma patient, were harder to be mineralized. Herein, rat calvarial osteoblasts were used as our model to evaluate the effects of estradiol on ATP synthesis and cell mineralization. Aging can reduce systemic hormone levels and mitochondrial energy metabolism [18]. This study provides an alternative pathway to clarify the roles of the estrogen/ER $\alpha$ axis in aging-induced bone diseases.

Estrogen can improve osteoblast maturation. Osteoblasts, differentiated from stromal stem cells, remarkably contribute to bone formation [4]. Estradiol stimulated proliferation of osteoblasts. Proliferation of osteoblasts and their primitive osteoprogenitors is a vital process in osteogenesis [25]. Hence, estradiol-enhanced osteoblast proliferation is supportive of subsequent cell differentiation and maturation. Moreover, estradiol could elevate ALP activity. ALP, a biomarker of osteoblasts, is regularly assayed to evaluate osteoblast activities [27]. Zhou et al. showed that upregulation in ALP gene expression and enzyme activity is directly correlated with osteoblast differentiation [28]. Corresponding to enhancements in cell proliferation and ALP activity, our present results by Alizarin red S and von Kossa staining protocols further demonstrated that exposure of osteoblasts to estradiol led to significant development of cell calcification. A previous study reported a positive role of ER $\alpha$ in mediating resveratrol-induced proliferation of human bone marrow-derived mesenchymal stem cells and subsequent osteoblastic differentiation [29]. Also, studies from both Heim et al. and our lab stated that the phytoestrogen, genistein, can induce ER $\alpha$ expression and enhance osteogenesis [23, 30]. Herein, expression of ER $\alpha$ was induced in human osteoblasts by estradiol. Thus, estrogen-triggered $\mathrm{ER} \alpha$ may partake in maturation of osteoblasts induced by the sex hormone.

Specific genomic complex gene products contribute to estrogen/ER $\alpha$-induced osteoblast mineralization. In the inner membranes of mitochondria, four complexes and one ATP synthase are anchored together to transfer electrons from the donors of $\mathrm{NADH}$ and $\mathrm{FADH}_{2}$ via respiratory chain reactions $[10,11]$. These complexes are constructed of a variety of complex subunits encoded by chromosomal genes or mitochondrial DNAs [12]. This study showed the translocation of ER $\alpha$ from the cytoplasm to nuclei in human osteoblasts after exposure to estradiol. In nuclei, activated ER $\alpha$ dimers can have strong transcriptional activities to induce expressions of target genes by precisely binding to EREs existing in 5'-promoter regions $[14,21]$. Among these induced genomic complex genes, COX8A, COX6A2, COX8C, СОХ6C, СOХ6B2, and $C O X 412$ are subunits for construction of cytochrome c oxidase (complex IV); NDUFA10 is for NADH: ubiquinone oxidoreductase (complex I); and UQCRC1 is for coenzyme Q: cytochrome c oxidoreductase (complex III). Fascinatingly, ATP12A, a subunit of ATP synthase, was also induced by estradiol in human osteoblasts. Bettini and Maggi reported that estrogen can induce cytochrome c oxidase subunit III expression in the rat hippocampus, thus enhancing neuronal activity [31]. This study also demonstrated definite effects of estradiol on ER $\alpha$ expression. Therefore, one of the possible reasons explaining estrogen-induced mitochondrial biogenesis is ER $\alpha$-involved upregulation of the expressions of precise chromosomal complex I, III, and IV genes.

Mitochondrial COX I contributes to estrogen/ER $\alpha$ induced energy metabolism. COX I is a mitochondrialencoded complex enzyme. In complex IV, COX I functions as a core component to build up a redox-active center with other nuclear- and mitochondrial-encoded complex subunits [11]. Estradiol can work as a ligand to bind $\mathrm{ER} \alpha$ and stimulate translocation of this activated transcript factor from the cytoplasm to mitochondria in human osteoblasts. In parallel, the cox $i$ gene expression were induced by estradiol in both human osteoblasts and rat calvarial osteoblasts. Moreover, a bioinformatic search revealed the existence of EREs in the 5'-promoter region of the cox $i$ gene. Concurrently, knocking-down ER $\alpha$ translation using RNAi could inhibit estradiol-induced COX I mRNA expression. Thus, the estrogen/ER $\alpha$ signaling pathway is involved in regulating mitochondrial cox $i$ gene expression, and the mechanism may occur at a transcriptional level. Hsieh et al. reported that after traumahemorrhage, elevated estrogen levels were associated with increases in ER, COX I, and ATP contents [32]. In breast cancer MCF7 cells, estradiol was shown to increase levels of mitochondrial COX6c and ATP synthase, which may lead to drug resistance of cancer cells [33]. Cytochrome c oxidase is the terminal complex in the mitochondrial electron transport chain, and COX I is a main catalytic subunit in complex IV [34]. Therefore, this study provides cellular and molecular evidence to demonstrate that estrogen/ER $\alpha$-induced expression of COX 1 participates in regulating mitochondrial bioenergetics and osteoblast mineralization.

Estrogen stimulates mitochondrial activities, thus improving osteoblast calcification. ATP is an end product of aerobic respiratory chain reactions and functionally works as a coenzyme for intracellular energy transfer [10]. The present study demonstrated enhancing effects of estradiol on the MMP and ATP biosynthesis in human osteoblasts. Conservation of the MMP is necessary for respiratory 
electron transport and subsequent ATP biosynthesis [34]. Hence, estradiol can stimulate ATP production via elevating the MMP. Separately, mitochondrial enzyme activity was instantaneously augmented in human osteoblasts by estradiol. NADH: ubiquinone oxidoreductase, the largest respiratory complex, uses the reducing potential of $\mathrm{NADH}$ to drive protons from the matrix across the inner mitochondrial membrane into the intermembrane space to maintain the MMP [35]. Bonora et al. reported that elevation of mitochondrial complex I enzyme activity is closely associated with growth in the respirational rate and ATP synthesis [36]. Consequently, administration of estradiol to human osteoblasts can improve cellular energy production due to successive extensions in complex I enzyme activity, the MMP, and COX I expression. A previous study proved the effects of cellular ATP of stimulating differentiation and maturation of human osteoblast-like Saos-2 cells [37]. Furthermore, a decrease in mitochondrial energy metabolism may be linked to a variety of aging phenotypes, including osteoporosis [38]. The present study implies potential benefits of the estrogen/ER $\alpha$ axis for improving osteoblast maturation and bone formation by upgrading cellular ATP synthesis.

In conclusion, this study has shown considerable benefits of estradiol administration on osteoblast activities, proliferation, and mineralization. Estradiol specifically increased cellular ER $\alpha$ levels and its translocations to nuclei and mitochondria. The nuclear-activated ER $\alpha$ could specifically induce expressions of complex I, III, and IV and ATP synthase subunit genes. More interestingly, estradiol could induce mitochondrial COX I mRNA and protein expressions in osteoblasts via an ER $\alpha$-dependent mechanism. Consequently, treatment with estradiol increased the MMP, the mitochondrial enzyme activity, and ATP biosynthesis. Taken together, this study showed the participation of the estrogen/ER $\alpha$ axis in osteoblast maturation through improving cellular ATP synthesis because of definite upregulation of expressions of chromosomal and mitochondrial complex subunit genes. However, this study possessed certain research limitations. Our present data cannot explain why estradiol induced COX II mRNA expression but did not affect its protein levels. More experiments, for example, analyzing COX II mRNA-specific RNase polynucleotide phosphorylase activity, are needed in our future study. Furthermore, translational studies using animal models of an ovariectomy and bone defects are being performed in our lab in order to supplementary confirm the roles of the estrogen/ER $\alpha$ signaling alliance in bone formation and fracture healing.

\section{MATERIALS AND METHODS}

\section{Preparation of rat osteoblasts}

Primary osteoblasts were prepared from 3-dayold Wistar rat calvaria following a previously described method [39]. All procedures were performed according to the National Institutes of Health Guidelines for Use of Laboratory Animals and were pre-approved by the Institutional Animal Care and Use Committee of WanFang Hospital, Taipei Medical University (Taipei, Taiwan). Osteoblasts were seeded in Dulbecco's modified Eagle's medium (DMEM; Gibco-BRL, Grand Island, NY, USA) supplemented with $10 \%$ heat-inactivated fetal bovine serum (FBS), L-glutamine, penicillin (100 IU/ml), and streptomycin $(100 \mu \mathrm{g} / \mathrm{ml})$ in $10-\mathrm{cm}$ tissue culture dishes at $37{ }^{\circ} \mathrm{C}$ in a humidified atmosphere of $5 \% \mathrm{CO}_{2}$. Osteoblasts were grown to confluence prior to drug treatment. Only the first passage of rat osteoblasts was used in this study.

\section{Cell morphology and ALP activity}

Rat calvarial osteoblasts were treated with a differentiation reagent, containing $10 \mathrm{nM}$ dexamethasone, $100 \mu \mathrm{g} / \mathrm{mL}$ ascorbic acid, and $10 \mathrm{mM} \beta$-glycerophosphate, and a combination of estradiol and the differentiation reagent for 21 days. $\beta$-Estradiol with a purity of $>98 \%$ was purchased from Sigma (St. Louis, MO, USA). After drug treatment, the cell morphology was observed and photographed using an inverted microscope (Nikon, Tokyo, Japan). The ALP enzyme activity of primary osteoblasts was determined by detecting the formation of p-nitrophenol, a product of p-nitrophenyl phosphate catalyzed by ALP, according to a previously described colorimetric procedure (Sigma) [40].

\section{Assays of osteoblast mineralization}

Osteoblast maturation was determined by evaluating cell mineralization using the von Kossa- and alizarin red $\mathrm{S}$ dye-staining protocols as described previously [41]. Rat calvarial osteoblasts were seeded in 6-cm tissue culture dishes and treated with a differentiation reagent, containing $10 \mathrm{nM}$ dexamethasone, $100 \mu \mathrm{g} / \mathrm{mL}$ ascorbic acid, and $10 \mathrm{mM} \beta$-glycerophosphate, and a combination of estradiol and the differentiation reagent for 21 days. After drug treatment, the cell morphology was observed and photographed using an inverted microscope (Nikon). Also, osteoblasts were washed with ice-cold phosphatebuffered saline (PBS, 0.14 M NaCl, $2.6 \mathrm{mM} \mathrm{KCl,} 8 \mathrm{mM}$ $\mathrm{Na}_{2} \mathrm{HPO} 4$, and $1.5 \mathrm{mM} \mathrm{KH}_{2} \mathrm{PO}_{4}$ ) and then fixed in ice-cold $10 \%$ formalin for $20 \mathrm{~min}$. For the von Kossa protocol, mineralized matrix was detected by treating fixed cells with $5 \%$ silver nitrate for $30 \mathrm{~min}$, followed by subsequent washes with $5 \%$ sodium carbonate in $10 \%$ formalin for 1 min and 5\% sodium thiosulfate for $5 \mathrm{~min}$. The reaction was stopped by washing cells twice with deionized water. For the alizarin red S dye protocol, fixed osteoblasts were thoroughly rinsed and then incubated in 1\% alcian blue at pH 2.5 (Thermo Fisher Scientific, Tewksbury, MA, USA) for $12 \mathrm{~h}$. Sections were then incubated in alizarin red $\mathrm{S}$ (Thermo Fisher Scientific) for $8 \mathrm{~min}$, dehydrated briefly 
in xylene, and covered with a coverslip in Permount (Thermo Fisher Scientific). Mineralized nodules were visualized under a light microscope (Nikon). Stained cells were dissolved in dimethyl sulfoxide, and signals were spectrophotometrically measured at a wavelength of 570 $\mathrm{nm}$ as described previously [42]. Each experiment was performed in duplicate wells and repeated three times.

\section{Assay of cell survival}

A trypan blue exclusion method was conducted to determine cell survival according to a previous study [43]. Briefly, human osteoblast-like U2OS cells, derived from a female osteosarcoma patient, were purchase from Bioresource Collection and Research Center (Hsinchu, Taiwan). Cells were seeded in 24-well tissue culture plates with DMEM (Gibco-BRL) supplemented with 10\% heatinactivated FBS, L-glutamine, penicillin (100 IU/ml), and streptomycin $(100 \mu \mathrm{g} / \mathrm{ml})$ at $37{ }^{\circ} \mathrm{C}$ in a humidified atmosphere of $5 \% \mathrm{CO}_{2}$. After drug treatment, human osteoblasts were trypsinized with $0.1 \%$ trypsin-EDTA (Gibco-BRL). After centrifugation and washing, cells were suspended in PBS and stained with trypan blue dye (Sigma). Fractions of dead cells with a blue signal were visualized and counted using a reverse-phase microscope (Nikon).

\section{Immunoblot analyses of $\mathrm{ER} \alpha, \mathrm{ER} \beta$, and $\beta$-actin}

Immunoblotting protein analyses were conducted following a previous method [44]. After drug treatment, cell lysates from human osteoblast-like cells were prepared in an ice-cold radioimmunoprecipitation assay (RIPA) buffer, containing $25 \mathrm{mM}$ Tris- $\mathrm{HCl}(\mathrm{pH} 7.2), 0.1 \%$ sodium dodecylsulfate (SDS), 1\% Triton X-100, 1\% sodium deoxycholate, $0.15 \mathrm{M} \mathrm{NaCl}$, and $1 \mathrm{mM}$ EDTA. A mixture of $1 \mathrm{mM}$ phenyl methyl sulfonyl fluoride, $1 \mathrm{mM}$ sodium orthovanadate, and $5 \mu \mathrm{g} / \mathrm{ml}$ leupeptin was added to the RIPA buffer in order to avoid degrading the cytosolic proteins by proteinases. Protein concentrations were quantified using a bicinchonic acid protein assay kit (Pierce, Rockford, IL, USA). Proteins (50 $\mu \mathrm{g} /$ well) were subjected to SDSpolyacrylamide gel electrophoresis (PAGE), and transferred to nitrocellulose membranes. Levels of $\mathrm{ER} \alpha$ and $\mathrm{ER} \beta$ proteins were immunodetected using rabbit polyclonal antibodies (pAbs, Santa Cruz Biotechnology, Santa Cruz, CA, USA) against human $\mathrm{ER} \alpha$ and $\mathrm{ER} \beta$, respectively. Cellular $\beta$-actin protein was analyzed using a mouse monoclonal antibody (mAb) against mouse $\beta$-actin (Sigma) as the internal control. These protein bands were quantified using a digital imaging system (UVtec, Cambridge, UK) as described previously [45].

\section{Confocal microscopic analyses of ERa translocation to nuclei and mitochondria}

Translocation of $\mathrm{ER} \alpha$ in human osteoblast-like cells to nuclei and mitochondria was performed using confocal microscopy according to a previously described method [46]. Briefly, after estradiol treatment, human osteoblasts were fixed with a fixing reagent (acetone: methanol, 1: 1) at $-20{ }^{\circ} \mathrm{C}$ for $10 \mathrm{~min}$. After rehydration, osteoblasts were reacted with $0.2 \%$ Triton $\mathrm{X}-100$ at room temperature for $15 \mathrm{~min}$. A rabbit $\mathrm{pAB}$ against human ER $\alpha$ (Santa Cruz Biotechnology) was used in this study to detect ER $\alpha$ in whole cells, including the cytoplasm, nuclei, and mitochondria. Immunodetection of ER $\alpha$ in human osteoblasts was carried out at $4{ }^{\circ} \mathrm{C}$ overnight. After washing, cells were sequentially reacted with a secondary antibody and biotin-[define?]SPconjugated AffiniPure goat anti-rabbit immunoglobulin G (IgG) (Jackson ImmunoResearch, West Grove, PA, USA) at room temperature for $1 \mathrm{~h}$. Following washing, the third antibody with Cy3-conjugated streptavidin (Jackson ImmunoResearch) was added to osteoblasts and reacted at room temperature for $30 \mathrm{~min}$. Nuclei and mitochondria of fixed osteoblasts were respectively stained with 4',6-diamidino-2-phenylindole (DAPI) and 3,3'-dihexyloxacarbocyanine (DiOC6) (Molecular Probes, Eugene, OR, USA), a positively charged dye, at $37{ }^{\circ} \mathrm{C}$ for $30 \mathrm{~min}$. A confocal laser scanning microscope (model FV500, Olympus, Tokyo, Japan) was used for sample observation. The excitation wavelength was set to $568 \mathrm{~nm}$, while a $585-\mathrm{nm}$ long-pass filter was used to collect the emitted light. Illumination of the existence of the $\mathrm{ER} \alpha$ protein was demonstrated by the appearance of "hot spots" in the cytoplasm, nuclei, and mitochondria. Images were acquired and quantified using FLUOVIEW software (Olympus). The increased densities of hot spots were analyzed by automated recordings within the same region in a cell. The average density of hot spots was the average of values for 10 areas within a cell.

\section{Bioinformatic approach}

Estrogen response elements (EREs, 13 base pairs, GGTCAnnnTGACC) in the promoter region of the mitochondrial cox I and cox II genes were predicted using the PROMO bioinformatic system as described previously $[46,47]$. Our results respectively indicated that there were four and six predicted ERE sites located in the 5' promoter regions of the mitochondrial cox $i$ and cox $i i$ genes.

\section{Reverse-transcription (RT) and quantitative PCR assays}

Expressions of mitochondrial COX I and COX II messenger (m)RNA in human osteoblasts were determined using RT-PCR analyses as described previously [48]. After drug treatment, total RNAs were prepared for analyses of mitochondrial COX I and COX II, and $\beta$-actin mRNA. Oligonucleotide primers were designed and synthesized by MDBio (Taipei, Taiwan). Oligonucleotide sequences of the respective upstream and downstream primers 
were 5'-TACGTTGTAGCCCACTTCCACT-3' and 5'- GGATAGGCCGAGAAAGTGTTGT -3' for COX I mRNA; 5'- GTAGTACTCCCGATTGAAGCCC-3' and 5'-ATTCTAGGACGATGGGCATGAA-3' for COX II mRNA; and 5'-ATGGATGATGATATCGCCGCGCTC GTCGTC-3' and 5'-AGGGTGAGGATGCCTCTCTTG CTCTG-3' for $\beta$-actin mRNA [49]. These mRNAs were reverse-transcribed into their cDNAs. Amplification of these COX I, COX II, and $\beta$-actin cDNAs was performed with an initial denaturation at $94{ }^{\circ} \mathrm{C}$ for $5 \mathrm{~min}$, followed by 35 cycles $\left(94^{\circ} \mathrm{C}\right.$ for $45 \mathrm{~s}, 55^{\circ} \mathrm{C}$ for $\mathrm{COI}$ and COII and $60{ }^{\circ} \mathrm{C}$ for $\beta$-actin for $45 \mathrm{~s}, 72^{\circ} \mathrm{C}$ for $90 \mathrm{~s}$ ), a final extension step at $72{ }^{\circ} \mathrm{C}$ for $10 \mathrm{~min}$, and a stopping step at $4{ }^{\circ} \mathrm{C}$. PCR products were loaded onto a $1.8 \%$ agarose gel containing $0.1 \mu \mathrm{g} / \mathrm{ml}$ ethidium bromide and electrophoretically separated. DNA bands were visualized and photographed under ultraviolet-light exposure. Intensities of the DNA bands in the agarose gel were quantified with the aid of a digital imaging system (UVtec). A quantitative PCR analysis was carried out using iQSYBR Green Supermix (Bio-Rad, Hercules, CA, USA) and the MyiQ SingleColor Real-Time PCR Detection System (Bio-Rad) as described previously [43].

\section{Protein analyses of mitochondrial COX I and COX II}

Protein analyses were carried out according to a previously described method [50]. After drug treatment, cell lysates from human osteoblasts were prepared in ice-cold RIPA buffer. To avoid protein degradation, a proteinase inhibitor mixture, containing $1 \mathrm{mM}$ phenyl methyl sulfonyl fluoride, $1 \mathrm{mM}$ sodium orthovanadate, and $5 \mu \mathrm{g} / \mathrm{ml}$ leupeptin was added to the assay buffer. Protein concentrations were quantified using a bicinchonic acid protein assay kit (Pierce). Proteins $(50 \mu \mathrm{g} /$ well) were subjected to SDS-PAGE, and transferred to nitrocellulose membranes. Amounts of mitochondrial COX I protein were immunodetected using a mouse $\mathrm{mAb}$ against human COX I (Abcam, Cambridge, UK). Mitochondrial COX II protein was detected with a rabbit $\mathrm{pAb}$ against human COX II (GeneTex, Irvine, CA, USA). Levels of the $\beta$-actin protein were immunodetected using a mAb (Sigma) as the internal standard. These protein bands were quantified using a digital imaging system (UVtec).

\section{ERa knockdown}

Expression of ER $\alpha$ in human osteoblasts was knocked-down using an RNA interference (RNAi) method following a small interfering (si)RNA transfection protocol provided by Santa Cruz Biotechnology as described previously [27]. ER $\alpha$ siRNA was a pool of 3 target-specific 20-25-nt siRNAs designed to knock-down ER $\alpha$ 's expression. After culturing human osteoblasts in antibiotic-free DMEM at $37{ }^{\circ} \mathrm{C}$ in a humidified atmosphere of $5 \% \mathrm{CO}_{2}$ for 24 or $48 \mathrm{~h}$, the siRNA duplex solution, which was diluted in the siRNA transfection medium (Santa Cruz Biotechnology), was added to the osteoblasts. Scrambled siRNA, purchased from Santa Cruz Biotechnology, was applied to control cells as a negative standard. After transfection for 24 or $48 \mathrm{~h}$, the medium was replaced with normal DMEM, and the bone cells were treated with estradiol.

\section{Quantification of the mitochondrial membrane potential (MMP)}

The MMP was determined following a previously described method [51]. Briefly, human osteoblasts $\left(5 \times 10^{5}\right.$ cells) were seeded in 12-well tissue culture plates overnight. After administration of estradiol, osteoblasts were harvested and incubated with 3,30-dihexyloxacarbocyanine iodide (DiOC6), an intracellular green-fluorescent probe specifically used to detect the MMP in live cells, at $37^{\circ} \mathrm{C}$ for $30 \mathrm{~min}$ in a humidified atmosphere of 5\% CO2. After washing and centrifugation, cell pellets were suspended in PBS. Intracellular fluorescent intensities were analyzed using a flow cytometer (Olympus).

\section{Assay of the mitochondrial enzyme activity}

The mitochondrial enzyme activation was assayed by determining activity of $\mathrm{NAD}(\mathrm{P}) \mathrm{H}$-dependent cellular oxidoreductase enzymes using a colorimetric method [23]. After administration of estradiol and the differentiation agent, human osteoblasts were cultured with a new medium containing $0.5 \mathrm{mg} / \mathrm{ml} \mathrm{3-(4,5-dimethylthiazol-}$ 2-yl)-2,5-diphenyltetrazolium bromide for a further $3 \mathrm{~h}$. Blue formazan products in the osteoblasts were dissolved in dimethyl sulphoxide and spectrophotometrically measured at a wavelength of $550 \mathrm{~nm}$.

\section{Measurement of cellular ATP}

The levels of cellular ATP in human osteoblasts were determined by a bioluminescence assay based on the luciferase requirement for ATP in producing emission light, according to the protocol for the Molecular Probes ATP Determination Kit (Molecular Probes, Eugene, OR) as describe previously [52]. The luminant light (560 nm) emitted by the luciferasemediated reaction of ATP and luciferin was detected by a WALLAC VICTOR $® 1420$ multilabel counter (Welch Allyn, Turku, Finland).

\section{Statistical analysis}

Statistical differences between the control and drug-treated groups were considered significant when the $p$ value of Duncan's multiple-range test was $<0.05$. Statistical analyses between drug-treated groups were carried out using two-way analysis of variance (ANOVA). 


\section{Author contributions}

Conception and design: P.I. Lin and R.M. Chen.

Development of methodology: P.I. Lin and R.M. Chen.

Acquisition of data: P.I. Lin, Y.T. Tai, W.P. Chan, and Y.L. Lin.

Analysis and interpretation of data: Y.T. Tai, M.H. Liao, Chang, and R.M. Chen.

Writing, review, and/or revision of the manuscript: P.I. Lin, Y.T. Tai, and R.M. Chen.

Administrative, technical, or material support: P.I. Lin, Y.T. Tai, and R.M. Chen.

Study supervision: R.M. Chen.

\section{ACKNOWLEDGMENTS}

The authors thank the Core Facility, Office of Research and Development, Taipei Medical University for their assistance in processing the collection and analyses of confocal images.

\section{CONFLICTS OF INTEREST}

The authors declare that no conflicts of interest exist.

\section{GRANT SUPPORT}

This study was supported by the Ministry of Science and Technology (NSC101-2314-B-038-0039-MY3 and MOST104-2314-B-038-004-MY3) and Wan Fang Hospital (105-wf-eva-02), Taipei, Taiwan.

\section{REFERENCES}

1. Black DM, Rosen CJ. Clinical practice. postmenopausal osteoporosis. N Engl J Med. 2016; 374:254-262.

2. Weaver CM, Gordon CM, Janz KF, Kalkwarf HJ, Lappe JM, Lewis R, O'Karma M, Wallace TC, Zemel BS. The national osteoporosis foundation's position statement on peak bone mass development and lifestyle factors: a systematic review and implementation recommendations. Osteoporos Int. 2016; 27:1281-1386.

3. Almeida M, Laurent MR, Dubois V, Claessens F, O'Brien CA, Bouillon R, Vanderschueren D, Manolagas SC. Estrogens and androgens in skeletal physiology and pathophysiology. Physiol Rev. 2017; 97:135-187.

4. Sapir-Koren R, Livshits G. Osteocyte control of bone remodeling: is sclerostin a key molecular coordinator of the balanced bone resorption-formation cycles? Osteoporos Int. 2014; 25:2685-2700.

5. Shevde NK, Bendixen AC, Dienger KM, Pike JW. Estrogens suppress RANK ligand-induced osteoclast differentiation via a stromal cell independent mechanism involving c-Jun repression. Proc Natl Acad Sci U S A. 2000; 97:7829-7834.

6. Khosla S, Oursler MJ, Monroe DG. Estrogen and the skeleton. Trends Endocrinol Metab. 2012; 23:576-581.

7. Kousteni S, Bellido T, Plotkin LI, O’Brien CA, Bodenner DL, Han L, Han K, DiGregorio GB, Katzenellenbogen JA, Katzenellenbogen BS, Roberson PK, Weinstein RS, Jilka RL, Manolagas SC. Nongenotropic, sex-nonspecific signaling through the estrogen or androgen receptors: dissociation from transcriptional activity. Cell. 2001; 104:719-730.

8. Nakamura T, Imai Y, Matsumoto T, Sato S, Takeuchi K, Igarashi K, Harada Y, Azuma Y, Krust A, Yamamoto Y, Nishina H, Takeda S, Takayanagi H, et al. Estrogen prevents bone loss via estrogen receptor alpha and induction of fas ligand in osteoclasts. Cell. 2007; 130:811-823.

9. Huang T, Liu R, Fu X, Yao D, Yang M, Liu Q, Lu WW, $\mathrm{Wu} \mathrm{C}$, Guan M. Aging reduces an ERRalpha-directed mitochondrial glutaminase expression suppressing glutamine anaplerosis and osteogenic differentiation of mesenchymal stem cells. Stem Cells. 2017; 35:411-424.

10. Kehrein K, Bonnefoy N, Ott M. Mitochondrial protein synthesis: efficiency and accuracy. Antioxid Redox Signal. 2013; 19:1928-1939.

11. Dennerlein S, Rehling P. Human mitochondrial COX1 assembly into cytochrome c oxidase at a glance. J Cell Sci. 2015 ; $128: 833-837$.

12. Lenaz G, Genova ML. Structure and organization of mitochondrial respiratory complexes: a new understanding of an old subject. Antioxid Redox Signal. 2010; 12:961-1008.

13. Vega RB, Horton JL, Kelly DP. Maintaining ancient organelles: mitochondrial biogenesis and maturation. Circ Res. 2015; 116:1820-1834.

14. Rettberg JR, Yao J, Brinton RD. Estrogen: a master regulator of bioenergetic systems in the brain and body. Front Neuroendocrinol. 2014; 35:8-30.

15. Brinton RD. The healthy cell bias of estrogen action: mitochondrial bioenergetics and neurological implications. Trends Neurosci. 2008; 31:529-537.

16. Yao J, Brinton RD. Estrogen regulation of mitochondrial bioenergetics: implications for prevention of Alzheimer's disease. Adv Pharmacol. 2012; 64:327-371.

17. Hsieh YC, Frink M, Choudhry MA, Bland KI, Chaudry IH. Metabolic modulators following trauma sepsis: sex hormones. Crit Care Med. 2007; 35:S621-S629.

18. Suliman HB, Piantadosi CA. Mitochondrial quality control as a therapeutic target. Pharmacol Rev. 2016; 68:20-48.

19. Sims NA, Clément-Lacroix P, Minet D, FraslonVanhulle C, Gaillard-Kelly M, Resche-Rigon M, Baron R. A functional androgen receptor is not sufficient to allow estradiol to protect bone after gonadectomy in estradiol receptordeficient mice. J Clin Invest. 2003; 111:1319-1327. 
20. Klinge CM. Estrogen receptor interaction with estrogen response elements. Nucleic Acids Res. 2001; 29:2905-2919.

21. Jacob J, Sebastian KS, Devassy S, Priyadarsini L, Farook MF, Shameem A, Mathew D, Sreeja S, Thampan RV. Membrane estrogen receptors: genomic actions and post transcriptional regulation. Mol Cell Endocrinol. 2006; 246:34-41.

22. Manolagas SC, O'Brien CA, Almeida M. The role of estrogen and androgen receptors in bone health and disease. Nat Rev Endocrinol. 2013; 9:699-712.

23. Liao MH, Tai YT, Cherng YG, Liu SH, Chang YA, Lin PI, Chen RM. Genistein induces estrogen receptor- $\alpha$ gene expression in osteoblasts through activation of MAPKs/ $\mathrm{NF}-\kappa \mathrm{B} / \mathrm{AP}-1$ and promotes cell mineralization. Br J Nutr. 2014; 111:55-63.

24. Giustina A, Mazziotti G, Canalis E. Growth hormone, insulin-like growth factors, and the skeleton. Endocrine Rev. 2008; 29:535-559.

25. Chan CK, Seo EY, Chen JY, Lo D, McArdle A, Sinha R, Tevlin R, Seita J, Vincent-Tompkins J, Wearda T, Lu WJ, Senarath-Yapa K, Chung MT, et al. Identification and specification of the mouse skeletal stem cell. Cell. 2015; 160:285-298.

26. Turner $\mathrm{CH}$, Robling AG. Mechanisms by which exercise improves bone strength. J Bone Miner Metab. 2005; 23:16-22.

27. Wu GJ, Wang W, Lin YL, Liu SH, Chen RM. Oxidative stress-induced apoptotic insults to rat osteoblasts are attenuated by nitric oxide pretreatment via gata-5involved regulation of $\mathrm{Bcl}-X_{L}$ gene expression and protein translocation. Arch Toxicol. 2016; 90:905-916.

28. Zhou H, Choong P, McCarthy R, Chou ST, Martin TJ, Ng KW. In situ hybridization to show sequential expression of osteoblast gene markers during bone formation in vivo. $\mathrm{J}$ Bone Miner Res. 1994; 9:1489-1499.

29. Dai Z, Li Y, Quarles LD, Song T, Pan W, Zhou H, Xiao Z. Resveratrol enhances proliferation and osteoblastic differentiation in human mesenchymal stem cells via ER-dependent ERK1/2 activation. Phytomedicine. 2007; 14:806-814

30. Heim M, Frank O, Kampmann G, Sochocky N, Pennimpede T, Fuchs P, Hunziker W, Weber P, Martin I, Bendik I. The phytoestrogen genistein enhances osteogenesis and represses adipogenic differentiation of human primary bone marrow stromal cells. Endocrinology. 2004; 145:848-859.

31. Bettini E, Maggi A. Estrogen induction of cytochrome c oxidase subunit III in rat hippocampus. J Neurochem. 1992; 58:1923-1929.

32. Hsieh YC, Yang S, Choudhry MA, Yu HP, Bland KI, Schwacha MG, Chaudry IH. Flutamide restores cardiac function after trauma-hemorrhage via an estrogendependent pathway through upregulation of PGC-1. Am J Physiol Heart Circ Physiol. 2006; 290:H416-H423.
33. Chang FW, Fan HC, Liu JM, Fan TP, Jing J, Yang CL, Hsu RJ. Estrogen enhances the expression of the multidrug transporter gene ABCG2-increasing drug resistance of breast cancer cells through estrogen receptors. Int J Mol Sci. 2017; 18:163. https://doi.org/10.3390/ijms18010163.

34. Srinivasan S, Avadhani NG. Cytochrome c oxidase dysfunction in oxidative stress. Free Radic Biol Med. 2012; 53:1252-1263.

35. Zhu J, Vinothkumar KR, Hirst J. Structure of mammalian respiratory complex I. Nature. 2016; 536:354-358.

36. Bonora E, Porcelli AM, Gasparre G, Biondi A, Ghelli A, Carelli V, Baracca A, Tallini G, Martinuzzi A, Lenaz G, Rugolo M, Romeo G. Defective oxidative phosphorylation in thyroid oncocytic carcinoma is associated with pathogenic mitochondrial DNA mutations affecting complexes I and III. Cancer Res. 2006; 66:6087-696.

37. Cutarelli A, Marini M, Tancredi V, D’Arcangelo G, Murdocca M, Frank C, Tarantino U. Adenosine triphosphate stimulates differentiation and mineralization in human osteoblast-like Saos-2 cells. Dev Growth Differ. 2016; 58:400-408.

38. Bratic I, Trifunovic A. Mitochondrial energy metabolism and ageing. Biochim Biophys Acta. 2010; 1797:961-967.

39. Chen RM, Lin YL, Chou CW. GATA-3 transduces survival signals in osteoblasts through upregulation of $b c l-x_{L}$ gene expression. J Bone Min Res. 2010; 25:2193-2204.

40. Ho WP, Chan WP, Hsieh MS, Chen RM. Runx2-mediated $B c l-2$ gene expression contributes to nitric oxide protection against oxidative stress-induced osteoblast apoptosis. J Cell Biochem. 2009; 108:1084-1093.

41. Ho MH, Liao MH, Lin YL, Lai CH, Lin PI, Chen RM. Improving effects of chitosan nanofiber scaffolds on osteoblast proliferation and maturation. Int J Nanomed. 2014; 9:4293-4304.

42. Fang HW, Kao WY, Lin PI, Chang GW, Hung YJ, Chen RM. Effects of polypropylene carbonate/poly (D, L-lactic) acid/tricalcium phosphate elastic composites on improving osteoblast maturation. Ann Biomed Eng. 2015; 43:1999-2009.

43. Chang CY, Lui TN, Lin JW, Lin YL, Hsing CH, Wang JJ, Chen RM. Roles of microRNA-1 in hypoxia-induced apoptotic insults to neural cells. Arch Toxicol. 2016; 90:191-202.

44. Lin CJ, Lin YL, Luh F, Yen Y, Chen RM. Preclinical effects of CRLX101, an investigational camptothecincontaining nanoparticle drug conjugate, on treating glioblastoma multiforme via apoptosis and antiangiogenesis. Oncotarget. 2016; 7:42408-42421. https://doi.org/10.18632/ oncotarget.9878.

45. Yeh PS, Wang W, Chang YA, Lin CJ, Wang JJ, Chen RM. Honokiol induces autophagy of neuroblastoma cells through activating the PI3K/Akt/mTOR and endoplasmic reticular stress/ERK1/2 signaling pathways and suppressing cell migration. Cancer Lett. 2016; 370:66-77. 
46. Liao MH, Lin PI, Ho WP, Chan WP, Chen TL, Chen RM. Participation of GATA-3 in regulation of bone healing through transcriptionally upregulating $b c l-x_{L}$ gene expression. Exp Mol Med. 2017; 49:e398.

47. Farré D, Roset R, Huerta M, Adsuara JE, Roselló L, Albà MM, Messeguer X. Identification of patterns in biological sequences at the ALGGEN server: PROMO and MALGEN. Nucleic Acids Res. 2003; 31:3651-3653.

48. Ho MH, Yao CJ, Liao MH, Lin PI, Liu SH, Chen RM. Chitosan nanofiber scaffold improves bone healing via stimulating trabecular bone production due to upregulation of the Runx2/osteocalcin/alkaline phosphatase signaling pathway. Int J Nanomed. 2015; 10:5941-554.

49. Liu D, Gu X, Scafidi J, Davis AE. N-linked glycosylation is required for $\mathrm{cl}$ inhibitor-mediated protection from endotoxin shock in mice. Infect Immun. 2004; 72:1946-1955.

50. Lin CJ, Chang YA, Lin YL, Chio CC, Chen RM. Preclinical effects of honokiol on treating glioblastoma multiforme via G1 phase arrest and cell apoptosis. Phytomedicine. 2016; 23:517-527.

51. Lin JW, Chen JT, Hong CY, Lin YL, Wang KT, Yao CJ, Lai GM, Chen RM. Honokiol traverses the blood-brain barrier and induces apoptosis of neuroblastoma cells via an intrinsic Bax-mitochondrion-cytochrome c-caspase protease pathway. Neuro Oncol. 2012; 14:302-314.

52. Chen RM, Wu CH, Chang HC, Lin YL, Sheu JR, Chen TL. Propofol suppresses macrophage functions through modulating mitochondrial membrane potential and cellular adenosine triphosphate levels. Anesthesiology. 2003; 98:1178-1185. 